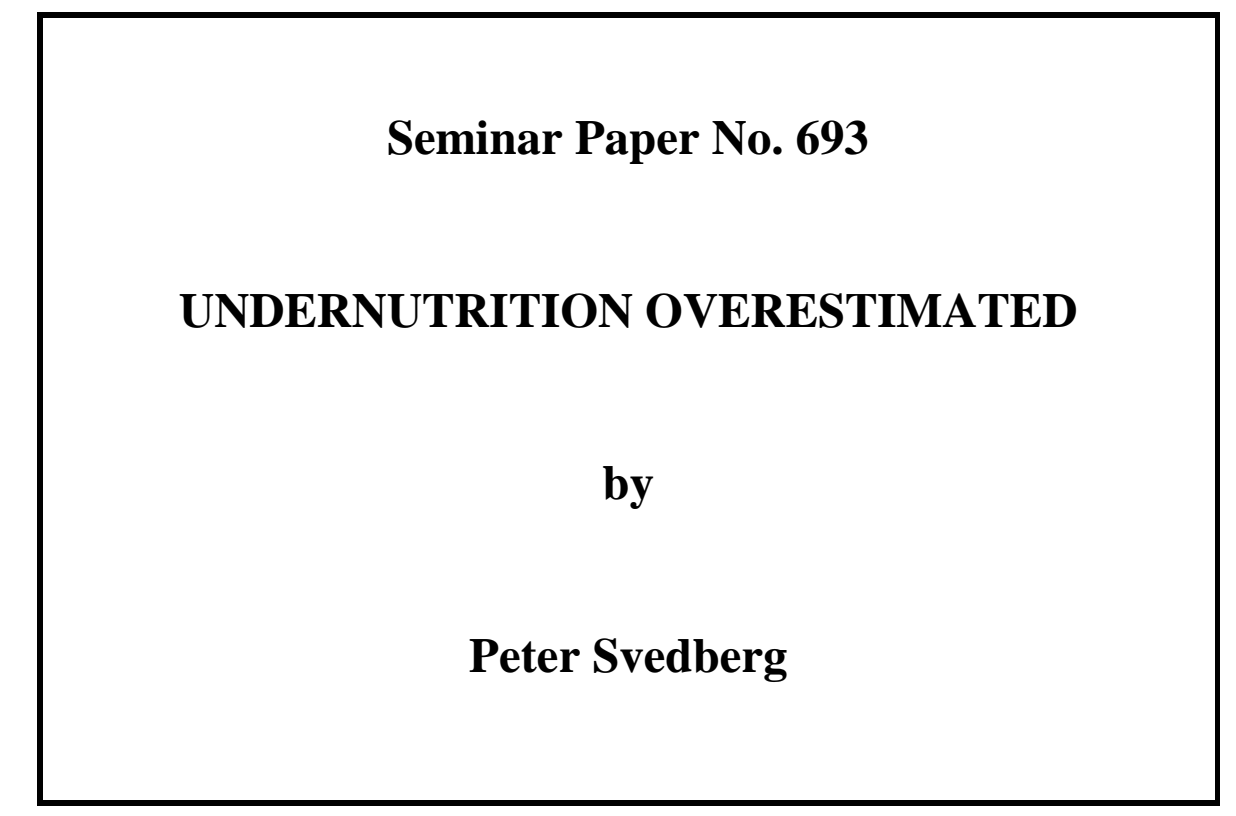

\title{
UNDERNUTRITION OVERESTIMATED
}

\section{Peter Svedberg}

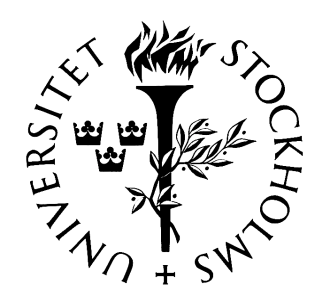

INSTITUTE FOR INTERNATIONAL ECONOMIC STUDIES Stockholm University 
Seminar Paper No. 693

\title{
UNDERNUTRITION OVERESTIMATED
}

\author{
by \\ Peter Svedberg
}

Papers in the seminar series are also published on internet in Adobe Acrobat (PDF) format.

Download from http://www.iies.su.se/

Seminar Papers are preliminary material circulated to stimulate discussion and critical comment.

October 2001

Institute for International Economic Studies

S-106 91 Stockholm

Sweden 


\title{
Undernutrition Overestimated*
}

Peter Svedberg

Institute for International Economic Studies, Stockholm University

\author{
"It is not easy to think of any social problem in the \\ contemporary world that deserves greater attention \\ than the foggy adversity of chronic and \\ widespread undernutrition,"**
}

\section{Introduction}

Chronic undernutrition is widely considered one of the most deplorable tribulations of the poverty and misery in which large sections of the population in many parts of the world still live. Undernutrition is not only a consequence of poverty, however, but also a cause. Although seldom possible to quantify with the desirable accuracy, undernutrition reduces the productivity of people directly, and also indirectly, by making them more susceptible to illness. ${ }^{1}$ Undernutrition, especially among young children, also increases the risk of premature death. ${ }^{2}$ Moreover, undernutrition in infancy and childhood for those surviving is linked to chronic health problems in adulthood. Undernutrition may also slow down cognitive development during childhood and, hence, the accumulation of the 
human capital that has been demonstrated to be crucial for economic growth and poverty alleviation. ${ }^{3}$

In late 1996, heads of states and representatives of governments from 186 nations gathered at the World Food Summit in Rome to address "the world hunger problem". The summitteers unanimously agreed to reduce by half the absolute number of undernourished people in the world before the year 2015. For this worthy objective to be accomplished through new policy initiatives, a necessary, but far from sufficient, condition is that we know in what countries the "hunger problem" is the most prevalent. Otherwise it will be impossible to design and target the national and international policy interventions. Moreover, if undernourishment is to be halved before 2015, the initial number of undernourished must be known, and for monitoring progress, reliable time-series data are needed.

The Food and Agricultural Organisation (FAO) of the UN, which prepared the main policy documents for the World Food Summit and convened the event, claims to know the number of chronically undernourished. Based on estimates of national food "availability" and its distribution across households in most developing countries, the $\mathrm{FAO}^{4}$ purports that altogether 841 million people were chronically undernourished in 1990/92. ${ }^{5}$ FAO also asserts to know the prevalence of undernutrition (POU) in 98 individual countries and that these estimates are "fully comparable across countries". ${ }^{6}$ It ranges from close to nil in South Korea to well above 50 per cent in Afghanistan and half a dozen African countries. The FAO also claims to know how the POU has changed in the 98 countries since $1969 / 71$ and that it has appropriate data for monitoring progress towards the 2015 objective. Since the international community's efforts to attain this worthy objective - and also the monitoring - are to be based on the FAO analysis, its reliability is imperative. ${ }^{7}$

In previous work I have demonstrated how fragile the empirical basis is for most of the parameter values inserted into the model used by the FAO in its pursuit to estimate the POU in various parts of the world ${ }^{8}$ Keeping with the FAO model, I have also shown that the POU estimates are highly sensitive to slight alterations in these uncertain parameter values. The essence of this earlier work was to point out the large margins of uncertainty in the input data used by the 
FAO, rather than focusing on systematic biases in the estimation model and in the data, the objective of this paper. ${ }^{9}$

As has been shown by others, the estimation model used by the FAO has an in-built flaw that leads to biased estimates of POU irrespective of the accuracy of the data inserted into the calculations. An alternative "unbiased" estimation model was first suggested by Sukhatme ${ }^{10}$, a former chief statistician at the FAO; his model and the current FAO one are briefly replicated in section II below. Naiken, the present chief statistician at the FAO, conjectures that the alternative model was never used by Sukhatme in empirical work because all the data required were not available. ${ }^{11}$ Naiken further cites the lack of data as the reason why the FAO has not made use of that estimation method. ${ }^{12}$

The first contribution of this paper will be to demonstrate that with the data the FAO actually claims to possess, it could very well have used the "unbiased" method for the estimation of POU (section III). It will also be shown that when applying the "unbiased" estimation model, while using the FAO parameter values, the estimated POU becomes implausibly high (section IV). It will further be argued that this is a consequence of systematic biases in the parameter values inserted by the FAO in its calculations (section V). Re-estimation of the POU, applying the "unbiased" model and alternative parameter values that are found to be more adequate, suggests that the FAO estimates of POU are upward biased on a net basis (section VI). We can hence separate the downward bias induced in the FAO estimates of POU by the use of a faulty model and the upward bias induced by using inaccurate data for key parameters. The revised (net) lower estimates of POU square better with anthropometric observations, the main alternative indicators of undernutrition (section VII). On the basis of previous findings, suggestions for improvements in the FAO method for estimating POU are offered in the concluding section.

\section{Estimation Models and Data Needs}

The essence of how the Sukhatme type of model differs from the one applied by the FAO can be described with the help of Figure $1 .{ }^{13}$ The common starting point is that there is a distribution of per-capita calorie intakes and a distribution of minimum per-capita calorie requirements (MPCCR) across households in all 
populations. The habitual per-capita calorie intake (availability) of households is measured along the Y axis with a mean at $\mu_{\mathrm{y}}$. The households' MPCCR are measured along the $X$ axis with a mean at $\mu_{\mathrm{x}}$. The MPCCR is what is needed to (i) maintain the lowest body weight for given height that is consistent with health and (ii) to fuel "necessary" physical activity (elaborated below). The households with the lowest MPCCR are the ones with members who have relatively small bodies (e.g. young children), and where the adults are engaged in light physical work activities. The households at the highest end of the MPCCR distribution comprise mostly adults and adolescents and most members are engaged in heavy manual work activities.

That the joint distribution - truncated at the edges and depicted as an ellipse - stretches out in the south-west to north-east direction reflects an assumption that there is a positive (but not perfect) correlation between per-capita calorie intake and minimum requirement across households in the population. The $\beta$-line gives the regression slope for $(\mathrm{y}, \mathrm{x})$. The increasingly closer oval "iso-contures", as we move towards the joint means of $\mu_{\mathrm{x}}$ and $\mu_{\mathrm{y}}$, indicate that the density of the joint function assumes its highest value here. Or the other way around, as we move away from the joint mean in different directions, we find increasingly smaller percentages of the population.

(Figure 1 about here)

\section{A. POU Estimates with the Joint-Distribution Model}

The households in the joint distribution that are above the 45-degree line in Figure 1 have a higher habitual per-capita calorie intake (y) than they require to avoid undernutrition (x). That is, for all households (j) in this part of the joint distribution, $y_{j}>x_{j}$. These households are well-nourished in the sense that they have body weights and physical activity levels above the minima that are needed for health and functions. (Some of these households may be "over-nourished", i.e. being overweight or obese, but this subset is ignored in the following.) The households $(\mathrm{k})$ below the 45-degree line have intakes that fail to meet their specific MPCCR, signifying that $\mathrm{y}_{\mathrm{k}}<\mathrm{x}_{\mathrm{k}}$. These households are classified as undernourished. Quite obviously, the households on the 45-degree line have 
intakes that exactly match their minimum requirements $\left(\mathrm{y}_{\mathrm{i}}=\mathrm{x}_{\mathrm{i}}\right)$. The households below the 45-degree line, i.e. those in areas $\mathbf{c}$ and $\mathbf{b}$ (marked with different light shades), as a share of the total number of households, constitute what we will call an "unbiased" estimate of the prevalence of undernutrition.

In order to estimate the share of a population that is found in areas $\mathbf{c}$ and $\mathbf{b}$ (and hence obtain an unbiased POU estimate), data are required for all the parameters needed to solve the double integral:

$$
\int_{\infty}^{\infty} \int_{y}^{\infty} \frac{1}{2 \pi \sigma_{x}{ }^{\prime} \sigma_{y}{ }^{\prime} \sqrt{1-\rho^{2}}} \exp \left[-\frac{q(x, y)}{2}\right] d x d y
$$

where

$$
q(x, y)=\frac{1}{1-\rho^{2}}\left[\left(\frac{x-\mu_{x}^{\prime}}{\sigma_{x}{ }^{\prime}}\right)^{2}-2 \rho\left(\frac{x-\mu_{x}^{\prime}}{\sigma_{x}^{\prime}}\right)\left(\frac{y-\mu_{y}^{\prime}}{\sigma_{y}{ }^{\prime}}\right)+\left(\frac{y-\mu_{y}^{\prime}}{\sigma_{y}{ }^{\prime}}\right)^{2}\right]
$$

and

$$
\begin{aligned}
& \mu_{i}{ }^{\prime}=\log \mu_{i}-\frac{1}{2} \log \left(C V_{i}^{2}+1\right) \quad i \in\{x, y\} \\
& \sigma_{i}{ }^{\prime}=\sqrt{\log \left(C V_{i}^{2}+1\right)} \quad i \in\{x, y\}
\end{aligned}
$$

where $(\rho)$ is the correlation coefficient between household per-capita calorie intake and minimum requirement and the two $\sigma$ 's are the standard deviations in the availability and requirement distributions. In the calculations to be carried out on the basis of equations ( 1 to 4 ) below, it will be assumed that the joint distribution is log-normal. ${ }^{14}$ (For expository convenience, the distribution in Figure 1 was depicted as joint normal.)

\section{B. POU Estimates with the FAO Model}

The FAO starts out by estimating the per-capita availability of calories $\left(\mu_{\mathrm{y}}\right)$ in individual countries and the standard deviation in the distribution of the available calories across households $\left(\sigma_{\mathrm{y}}\right)$ in respective country. Subsequently, the FAO sets up a norm for what is the "lowest acceptable" MPCCR for all households in respective population, called the calorie cut-off point (CCOP). In Figure 1, this 
cut-off point is $\delta_{\mathrm{x}}$. All households with a per-capita intake (availability) below this point $\left(\mathrm{y}_{\mathrm{k}}<\delta_{\mathrm{x}}\right)$ are classified as undernourished by the FAO. These households, corresponding to areas a and c, as a share of the total population, is the estimated POU as derived by the FAO. (Area $\mathbf{a}$ is marked with heavy shade and bounded from above by the horizontal line $\mathrm{y}=\delta_{\mathrm{x}}$ and from below by the $45-$ degree line indicating $\mathrm{y}=\mathrm{x}$.)

The FAO estimation method hence reduces to solving the single integral:

$$
\int_{-\infty}^{\delta_{x}} \frac{1}{\sigma_{y}^{\prime} \sqrt{2 \pi}} \exp \left[-\frac{\left(y-\mu_{y}^{\prime}\right)^{2}}{2 \sigma_{y}^{\prime 2}}\right] d y
$$

At the face of it, this estimation model may seem less data demanding than the joint-distribution method, but as we shall see (in section IV.B), this turns out not to be the case.

From Figure 1 we immediately see that the FAO estimates contain two types of errors. The observations in area a are classified as undernourished while in fact being well-nourished; these are false positives. The observations in area $\mathbf{b}$ are classified as well-nourished, but are in fact undernourished; false negatives. If the number of false positives and false negatives differ, the POU estimates are either downward or upward biased ${ }^{15}$. Quite obviously, the relative size of the false positive and negatives depends on where the cut-off point is established.

In the official documents from the FAO there is no mentioning of biases. ${ }^{16}$ Here it is implicitly maintained that the cut-off points have been set at levels that ensure that the false positives and negatives are of equal size, and hence offsetting, in all countries. Before probing into the empirical validity of this possibility, we shall describe - as a stepping stone - how the FAO has derived its calorie cut-off points $\left(\delta_{\mathrm{x}}\right.$ in Figure 1$)$.

\section{The Calorie Cut-Off Points}


In deriving its calorie cut-off point for a country, the FAO begins by estimating the minimum per-capita calorie requirement for the average household $\left(\mu_{\mathrm{x}}\right)$ in the population. This estimate is derived from the following formula:

$$
\mu_{\mathrm{x}}=\Sigma \alpha_{\mathrm{i}} \mathrm{PAL}_{\mathrm{i}}\left[\mathrm{BMR}_{\mathrm{i}}\left(\mathrm{W}_{\mathrm{i}}\right)\right] \text {, for } \mathrm{i}=1 \ldots . . \mathrm{n} \text { age and sex categories. }
$$

BMR is the basal metabolic rate, which is the energy requirement for internal body functions during complete rest (sleep), and determined by body weight (W). Per kilo of body weight, the BMR is assumed to be identical across populations for each age and sex category (i). For adolescents and adults, the "desirable" weight (W) is set at the median of the range of body weights (for height) that is consistent with good health and physical functioning. This height-adjusted weight is derived from a body mass index (BMI) equal to $22.0 .{ }^{17} \mathrm{PAL}$ is the daily average physical activity level for the average (adult) person in the population that is compatible with functions and "economically necessary work". The PAL is expressed as a multiple of BMR, which means that if a particular physical activity requires an energy expenditure twice that of being asleep, the ensuing PAL is equal to $2.0 .{ }^{18}$ Finally, the $\alpha_{i}$ are the weights (shares) of different age and sex categories in the population in respective country. (The $\alpha$ vector is hence the only entity in relation (6) that is allowed to vary across regions/countries.)

In the first column of Table 1, we find what the FAO has estimated to be the MPCCR for the average household $\left(\mu_{\mathrm{x}}\right)$ in the five major geographical regions in the developing world. In column (2) we have what the FAO calls the "lowest acceptable" per-capita energy requirement, or the cut-off point it uses to delineate the undernourished households. The cut-off point $\left(\delta_{\mathrm{x}}\right)$ is derived as two standard deviations $\left(\sigma_{\mathrm{x}}\right)$ below the estimated MPCCR for the average household $\left(\mu_{\mathrm{x}}\right)$ in respective region:

$$
\delta_{\mathrm{x}}=\mu_{\mathrm{x}}-2 \sigma_{\mathrm{x}}
$$

We further have that the coefficient of variation is defined as: 


$$
\mathrm{CV}_{\mathrm{x}}=\sigma_{\mathrm{x}} / \mu_{\mathrm{x}}
$$

Substituting (7) into (8) and rearranging we get:

$$
\mathrm{CV}_{\mathrm{x}}=\left(1-\delta_{\mathrm{x}} / \mu_{\mathrm{x}}\right) / 2
$$

With the help of equation (9) one can hence put numbers on the distribution of the MPCCR that the FAO has worked with (although not published). ${ }^{19}$ It then turns out (Table 1, column 5) that the FAO has attached a specific value to the $\mathrm{CV}_{\mathrm{x}}$ parameter (0.075), which is the same for each and every region (and country).

(Table 1 about here)

Some of the details (but not all) on how the FAO has arrived at the precise number attached to the $\mathrm{CV}_{\mathrm{x}}$ parameter are traceable. ${ }^{20}$ It is acknowledged that "there is a range of energy requirements for individuals" related to "a range of body weights that are consistent with healthy individuals" and "a range physical activity levels that may be considered to be economically necessary". ${ }^{21}$ The lower limit for body weight for adults, set by the FAO, corresponds to a BMI of 18.5, a weight below which health risks have been identified in medical studies. This number implies a coefficient of variation in health-consistent body weight of about 0.08 (Appendix Table 1). Variations in requirements for other age cohorts, i.e. children and old people, may have been considered, but no details have been published.

The energy requirements for physical activity in work have been derived from laboratory measures of the average physical activity levels (PAL) needed to pursue the kind of job activities that most working-age people in the developing countries are engaged in. ${ }^{22}$ These estimated averages are subsequently scaled down somewhat, to what the FAO on normative grounds finds to be the minimum "desirable" work activity for adult individuals in all countries. ${ }^{23}$ The implicit coefficients of variation in the distribution of work activities are 0.078 for men and 0.046 for women. On this basis, the FAO estimates the minimum energy requirement during working hours corresponds to a PAL equal to 2.53 for men 
and 2.57 for women. ${ }^{24}$ By weighting the PALs for the different daily activities, the FAO arrives at an average PAL over the 24 hours of 1.55 for men and 1.56 for women (Appendix Table 1). These numbers are applied world-wide, irrespective of inter-country differences in job activities and work productivity.

\section{IV. “Unbiased" POU Estimates Possible?}

The FAO has refrained from estimating the POU with the joint-probability -distribution model, citing the lack of data on certain parameters. In this section we shall demonstrate that with the data the FAO actually claims to possess, one can derive estimates of POU based on the joint-distribution formula. Comparing these "unbiased" estimates with the ones actually derived by the FAO provides an indication of the size of the bias induced by the FAO estimation methodology, based on calorie cut-off points (while ignoring, for the time being, biases in the data).

\section{A. The Missing Parameters}

The two parameter values which the FAO claims are missing and prevent the use of the joint-distribution model are the standard deviation in the inter-household MPCCR distribution $\left(\sigma_{\mathrm{x}}\right)$ and the correlation between intake and minimum requirement across households $(\rho)$. As shown by Table 1, the first of these parameters $\left(\sigma_{\mathrm{x}}\right)$, has, in fact, been assigned a specific value by the FAO in its pursuit to establish the calorie cut-off points. There are no empirically based data on the second parameter $(\rho)$.

Theoretically, the $\rho$ can assume values in the range $(0 \leq \rho \leq 1)$. The zero value is obtained when there is no correlation whatsoever between per-capita calorie intakes and minimum requirements across households; the value unity is obtained when the correlation is perfect. Without presenting definitive numbers, the FAO maintains that "a high positive correlation between intake and requirement" should be expected ${ }^{25}$. This notion is based on the analysis provided by an expert committee involved in the preparations for the Fifth World Food Survey. The committee argues that the expected correlation should be high because "Most people have the ability to select their food intake in accordance with their energy requirement over the long term, since it is believed that 
regulatory mechanisms operate to maintain a balance between energy intake and energy requirement over long periods of time", ${ }^{26}$

In the absence of empirically derived values of the correlation coefficient $(\rho)$, what we do in the following is to set up a range of "plausible" values. We assume, in accordance with the FAO expert committee, that household per-capita calorie intake (effective demand) is a function of household minimum calorie requirement and other parameters, such as a preference for body weights and physical activity levels above the minimum health-consistent ones, and, hence, the income needed to satiate these preferences. If the household-specific minimum requirements explain 25 per cent of the total inter-household variability in habitual intakes in a population, as conventionally measured by adjusted $\mathrm{R}^{2}$, the ensuing $\rho$ takes the value $0.50\left(R^{2}=\rho^{2}\right)$. If varying minimum requirements explain 81 per cent of the variability in habitual intakes, $\rho$ assumes the value 0.90 . We hence interpret the FAO's, and the committee's, expectation that the correlation should be "high" to imply that it assumes a value in the range $(0.50 \leq$ $\rho \leq 0.90)$.

\section{B. The "Unbiased" POU Estimates}

With the range of plausible values of $\rho$, we have data for all the parameters needed to derive "unbiased" estimates of POU with the aid of the jointdistribution formula (equation 1). In Table 2 we see that whatever the number assigned to $\rho$ in the "high" range $(0.50<\rho<0.90)$, the estimated POU for all the major geographical regions does not change by more than a few percentage points. It also turns out that this robustness carries over to a wider range of $\rho$ values $(<0.50)$. Even under the extreme assumption that there is no correlation whatsoever between per-capita intakes and minimum requirements $(\rho=0)$, the "unbiased" estimates of POU remain largely unaltered. ${ }^{27}$

(Table 2 about here) 


\section{Comparing FAO with "Unbiased" POU Estimates}

The "unbiased" POU estimates are compared to the estimates derived by the FAO (first column), using CCOPs, in Table 3. The numbers in column (2) were obtained when we re-estimated POU with the FAO method. The reason for the discrepancy between columns (1) and (2) is that the FAO's regional estimates have been derived as weighted averages of estimates for individual countries (with the notable exception of Sub-Saharan Africa, which is presumably treated as one country by the FAO). Our re-estimates are derived on the basis of (aggregate) data for regional averages. We were not able to re-estimate POU the way the FAO has done for the simple reason that the country-specific "input" data on CCOPs and $\mathrm{CV}_{\mathrm{y}}$, used by the FAO, have not been published. The third column gives the "unbiased" estimates (for $\rho=0.70$ ), as reported in Table 2 .

(Table 3 about here)

The difference between the numbers in columns (2) and (3) in Table 3 suggests, first, that the FAO method - relying on CCOPs - leads to underestimation of POU in all major geographical regions for given (FAO) input data. In terms of Figure 1, this means that the observations in area a (the false positives) are much fewer than in area $\mathbf{b}$ (the false negatives). The FAO's implicit claim that its POU estimates are unbiased is hence rejected. ${ }^{28}$ Moreover, that the underestimation is larger for some regions than others implies that the crossregional comparability is compromised. ${ }^{29}$

\section{Are the FAO Data To Be Trusted?}

The implausible high POU estimates obtained when applying the "unbiased" method raises the question whether there is something wrong with FAO input data. (Also the non-compatibility between these estimates and the anthropometric indicators of undernutrition suggest this; $c f$. section VII.) In the following, we shall briefly discuss some doubts about the accuracy of the FAO's main parameter values. 


\section{A. The Minimum Per-Capita Calorie Requirement for Average Household}

Two of the core assumptions behind the establishment of the MPCCR for the average household, as derived by the FAO, are that the median of the range of health-consistent body weights corresponds to a BMI of 22.0 and that on average people should be able to work with an intensity given by a PAL multiple of 3.0 during work hours (Appendix Table 1). The first of these assumptions seems to square with empirical evidence and is accepted by most physiologists and nutritionists. If one accepts the normative justification for establishing standards for physical activity, also the second assumption seems non-controversial.

Two other core assumptions behind the MPCCR for the average household (as well as the lower-bound households) as estimated by the FAO are questionable, however. These are the assumptions that the BMR per kilo of body weight is (i) a constant (ii) of equal size for people of given age and sex in all populations. There has been a long and heated debate on the "constancy" issue. The FAO has sided with those who claim that the human body's ability to lower metabolism in the wake of low energy intake is too small to be considered. Since no widely accepted conclusion has emerged, the FAO position is ambiguous, but cannot be proved wrong. ${ }^{30}$

When it comes to the further assumption that BMR $/ \mathrm{kg}$ is identical across populations, however, there is reason to object. Several studies during the 1990s have shown that people in the "tropics" have on average about 10 per cent lower $\mathrm{BMR} / \mathrm{kg}$ than people in the "north". ${ }^{31}$ In establishing its calorie norms the FAO has used BMR $/ \mathrm{kg}$ data for northern populations and applied them world-wide. A 10 per cent lower BMR $/ \mathrm{kg}$, and hence MPCCR for the average household, would mean (cet par) cut-off points that are equally much lower ( $c f$. equation 6).

\section{B. The Calorie Requirement Distribution Estimates}

The lower bound of the range of health-consistent body weights for adolescents and adults that the FAO uses to derive its cut-off points $(\mathrm{BMI}=18.5)$ is widely accepted. The minimum allowance of energy for work (PAL) in the cut-off points (see Appendix Table 1) is established on normative grounds that can only be challenged by invoking other subjective arguments. 
There is one outright omission in the FAO calculations of the distribution of MPCCRs across households, however. As emphasised by Naiken", the "FAO has adopted an approach that considers the household rather than the individual as the unit of assessment" (italics added).$^{33}$ It is hence of consequence that one factor that has a notable influence on the variance in minimum per-capita calorie requirement across households is entirely left out in the FAO estimates: the fact that different households have different size and composition in terms of age and sex (although Naiken admits that it should not, had data been available).

There are, unfortunately, no ready-to-use estimates of the composition of households according to age, sex and size in the various countries of the world. What we shall do is to estimate the per-capita BMR and MPCCR for a few "typical" household categories with different size and age structures. For each household category, two sets of per-capita BMR and MPCCR estimates are derived (Table 4). One set is derived on the basis of BMR data used by the FAO itself. $^{34}$ The other set is estimated as 90 per cent of these, so as to account for the observation that people in the "tropics" have lower BMR/kg than northerners (the latter estimates are in italics).

(Table 4 about here)

The household categories with the lowest per-capita BMR, and hence MPCCR, are those with a young profile (categories A to D), comprising one or two adults and a few young children (with small bodies). The MPCCR estimates for these households are well below the FAO cut-off points at around 1,800. In the other tail of the requirement distribution, there are households with an "old" composition, with mainly adults and adolescents (category M), with a MPCCR well above the FAO norm.

What the examples in Table 4 reveal are that differences in household composition and size induce significant differences in per-capita calorie requirement for BMR (and hence MPCCR). It should further be noted that “young" households (categories A to D), with household heads (parents) in their twenties and children predominantly below the age of 10, comprise between 35 and 45 per cent of all households in the typical South Asian and African country. ${ }^{35}$ 


\section{The Calorie Availability Distribution Estimates}

The FAO has estimated the distribution of "available" calories across households with methods that differ from country to country depending on the kind of data obtainable: household expenditure surveys, estimates of household income distribution and, as the crudest method when all data are lacking, extrapolations from "neighbouring countries" ${ }^{36}$ The country-specific $\mathrm{CV}_{\mathrm{y}}$ estimates are not published, but the regional-average estimates are almost identical and hover around $0.30 .^{37}$

The lack of alternative data prevents re-estimation of the regional $\mathrm{CV}_{\mathrm{y}}$ parameters. What we can do is to "test" the plausibility of the availability distributions as estimated by the FAO. The lower (about 5 per cent) "tails" of the FAO household per-capita calorie availability distributions, by major geographical regions, are shown in Table 5.A. What the numbers in column (2) tell us is that in Sub-Saharan Africa and in South Asia (with $\mathrm{CV}_{\mathrm{y}} \approx 0.30$ as suggested by the FAO), the households in the lower tail of the distribution have an availability (intake) of calories of 820 respective 920 per capita and day on a habitual basis (the availability estimates are derived by the FAO as three-year averages).

(Table 5 about here)

It is doubtful whether a habitual per-capita intake of $820-920$ calories is feasible in a living household. These intakes are roughly half of the number of calories (about 1,800) that the FAO considers to be the minimum required to maintain the lowest body weight that is consistent with health $(\mathrm{BMI}=18.5)$ and relatively light daily physical activity ( $\mathrm{PAL} \approx 1.56$ ). More importantly, acknowledging that minimum requirements vary with household size and composition, an intake of 820 calories is only about two-thirds of the MPCCR as estimated for the household category with the lowest requirement (category A in Table 4), at 1,215 calories. Two-thirds of this MPCCR is only sufficient to maintain a BMI of about $12.4(=0.67 \times 18.5)$ and a PAL of $1.38(=1+0.67 \times 0.56)$ 
for adolescents and adults. It also implies body weights for age of young children about two-thirds of the "normal".

Clinical examinations have found that the critical low weight for height at which death occurs in adolescents and adults corresponds to a BMI of about 11 for males and 13 for females. ${ }^{38}$ The lowest daily physical activity level that is consistent with life at complete rest, called the "short-term survival requirement", is a PAL of about $1.27 .{ }^{39}$ Young children with only about $60-70$ per cent of the norm weight have been estimated to face a mortality risk that is five to six times the average in African and South Asian child populations, which means that the risk approaches unity. ${ }^{40}$

If it were that the (five per cent) households in the lowest tail of the intake distribution only have a habitual intake of 820-920 calories per capita and day (over a three-year period), we would witness permanent famine in Sub-Saharan Africa and South Asia. That is, tens of millions of people would die from outright starvation each year unrelated to war and natural catastrophes. Since there is no empirical evidence to support such a gruesome corollary, we tentatively conclude that the FAO has overestimated the inter-household variance in household intakes, at least in these two regions. ${ }^{41}$

\section{The National Per-Capita Calorie Availability Estimates}

An alternative or supplementary explanation for the implausible low calorie intakes in the lower tail of the intake distribution, especially in Sub-Saharan Africa and South Asia, is that the per-capita availability of calories in these two regions (and possibly elsewhere) has been underestimated by the FAO. For the African countries it has been demonstrated that this is most likely the case. ${ }^{42}$ The main reason is that very primitive methods for the enumeration of crop acreage are used throughout the region. This explanation does not carry over to South Asia, however. In fact, it was the examination of the introduction of modern crop estimation methods in this region which revealed that the primitive methods used here earlier (and still applied throughout Africa) led to the underestimation of cereal production by $20-25$ per cent on average. ${ }^{43}$

There is reason to expect that food "availability" is underestimated in most parts of the developing world, although less so than in Africa. A substantial share 
of the food produced in almost all developing countries is for subsistence, which tend to be underestimated in official statistics world-wide. ${ }^{44} \mathrm{~A}$ related problem is that minor food items in all countries, such as fruits, vegetables and poultry, are incompletely or not at all covered in the FAO statistics (as acknowledged in the Food Production Yearbooks in small print). There are, however, no quantitative data available that can help us put numbers on these biases and no reliable method for checking their consistency. ${ }^{45}$ We therefore choose the most cautious option possible: we accept the FAO food availability estimates at face value in the reestimations of POU in the next section. It should be noted, though, that underestimation of food (calorie) supplies, even if it defies quantification, in terms of direction, unambiguously leads to overestimation of POU (cet par).

\section{Re-Estimates of POU with Alternative Parameter Values}

In this section we re-estimate the POU with both the FAO and the jointdistribution methods, but using alternative values of the main parameters. Acknowledging that people in the "tropics" have repeatedly been estimated to have a 10 per cent lower BMR/kg than Caucasians, we presume that the minimum per-capita calorie requirement for the average household $\left(\mu_{\mathrm{x}}\right)$ is 10 per cent lower than asserted by the FAO. The revised estimates will further be based on the hypothesis that the FAO has overestimated the inter-household variability in percapita calorie availability $\left(\mathrm{CV}_{\mathrm{y}}\right)$ and underestimated the variability in per-capita calorie requirement $\left(\mathrm{CV}_{\mathrm{x}}\right)$. This means that only one of the four main parameters in the FAO estimations, national per-capita calorie availability $\left(\mu_{\mathrm{y}}\right)$, is left unaltered.

\section{A. The Alternative Distribution Parameter Values}

The $\mathrm{CV}_{\mathrm{y}}$ parameter is assumed to take two alternative values, 0.25 and 0.20 , respectively. These are below the value assigned to this parameter by the $\mathrm{FAO}(\approx$ 0.30 ), which was found to produce habitual intakes in the lower tail of the distribution that seem impossible in living households, at least in Africa and South Asia. The alternative numbers are not very solid but have some empirical support. IFPRI researchers have derived $\mathrm{CV}_{\mathrm{y}}$ estimates with relatively reliable methods in samples from five countries. For four of the samples, the estimated 
$\mathrm{CV}_{\mathrm{y}}$ 's are in the 0.17 to 0.27 range and the five-sample average is 0.256 , which is approximately equal to the higher of the two alternative values suggested here. The FAO itself has estimated $\mathrm{CV}_{\mathrm{y}}$ for other countries with much cruder methods (see above), but not published the results. Some of these estimates evidently turned out implausibly large or small, which the FAO has "rectified" by truncating them to be in the 0.20 to 0.35 range. ${ }^{46} \mathrm{It}$ is notable that the two alternative $\mathrm{CV}_{\mathrm{y}}$ values are within this range.

The $\mathrm{CV}_{\mathrm{x}}$ parameter is also assigned two alternative values, 0.125 and 0.15 , respectively. That these values are higher than the uniform value of $\mathrm{CV}_{\mathrm{x}}(0.075)$ from the FAO is to account for the fact that the FAO has ignored inter-household variation in MPCCR due to differences in household size and age/sex composition. The highest alternative value of $\mathrm{CV}_{\mathrm{x}}(0.15)$, together with a 90 per cent of the $\mu_{\mathrm{x}}$ value, produce calorie-cut off points (Table 5.B) that are some 10 to 20 per cent higher than the estimated MPCCR for the households with the lowest requirements (Category A in Table 4). ${ }^{47}$ These cut-off points square with the FAO principle that these should be set somewhat above the lower tail of the MPCCR distribution. $^{48}$

\section{B. Re-Estimation of POU with Alternative Parameter Values}

We first re-estimate POU with the FAO method, relying on cut-off points, but applying the alternative values of the key parameters (Table 6, panel A). The first set of revised estimates (column 2) suggests that the POU is practically nonexistent in three of the five major regions and 14 and 8 per cent in Sub-Saharan Africa and South Asia. The second set of revised estimates, based on parameter values somewhat further from the FAO ones (column 3), shows the POU ranging from 1 to 9 per cent in the five regions.

The POU estimates based on the joint-distribution method, and the alternative parameter values, are reported in Table 6.B (columns 2 and 3). Also these estimates are considerably below the ones derived with this method when based on the FAO input data (column 1). ${ }^{49}$ This applies also to Sub-Saharan Africa, although the estimated POU here is less sensitive to alternative parameter values than for other regions. ${ }^{50}$ The overall conclusion is hence that when empirically more reasonable values are attached to the key parameters, the 
estimated POU world-wide becomes considerably lower than purported by the FAO. This is so with both estimation methods.

(Table 6 about here)

\section{Comparison with Anthropometric Indicators}

\section{A. Anthropometric Measurements and Norms}

The shares of people who have weights and heights below established anthropometric norms are the main alternative indicators of the nutritional (and health) status of a population that can be used to check the trustworthiness of the FAO estimates of POU. The most commonly applied anthropometric indicators for pre-school children are the percentages below two standard deviations (-2sd) of the median height-for-age (H/A), weight-for-height $(\mathrm{W} / \mathrm{H})$, and weight-for-age (W/A) in a reference (norm) population. For adult women (aged 20-49 years), the most frequently used anthropometric indicators are the shares that have a body mass index (as defined in n. 17) below 18.5 and a height short of 1.45 meters. (For adult men, no widely agreed norms exist.) Since growth in stature ceases around the age of 20 independent of nutrition, however, height reveals practically nothing about an adult person's nutritional status (neither acute nor chronic), the concern here. The height of adult persons only indicate their historical nutritional and health status (during childhood and adolescence).

\section{B. Expected Correspondence between POU and Anthropometric Status}

In the absence of measurement biases, one would expect the share of young children in a country who are stunted (below the height-for-age norm) to be consistently higher than a POU estimate derived from national per-capita calorie availability. This expectation stems from the fact that inadequate access to calories is only one of many reasons behind child growth faltering. Other main reasons are frequent, prolonged and untreated illness that reduces the appetite and the absorption of nutrients in the body, and/or intestinal parasites that divert the 
energy. Also malnutrition (lack of crucial micro-nutrients in the form of minerals, vitamins and proteins) as well as physically and mentally depriving environments prevent children from fully utilising the energy in the food they ingest and to thwart growth in stature. ${ }^{51}$

The correspondence between estimates of POU in a country/region and the share of its population that is wasted (low weight for height) by anthropometric standards is of special concern. As we have seen in section III above, the lowest body weights that are health-consistent constitute the core determinants of the calorie cut-off points that the FAO sets up. What the FAO's estimates of POU basically measure is hence the share of the households in a particular country/region that has a habitual per-capita calorie intake which is insufficient to cover the energy expenditures (BMR) needed to maintain abovenorm body weights for the household members. One thus expects that direct anthropometric assessment of people's body weight in representative sample populations in a country/region should find — on average — roughly the same percentages to be wasted as predicted by the POU estimates.

\section{The Empirical Picture}

Estimates of the anthropometric status of young children and adult women in the major geographical regions are reported in Table 7 for the early 1990s. The hypothesis that the share of children who are stunted (column 2) is higher than the POU estimates from the FAO (column 1) is corroborated by the data for most of the regions. The only exception is Sub-Saharan Africa, the region for which the POU estimate is by far the highest. This abnormality strengthen our earlier suspicion that the FAO's estimate of POU for Africa is especially questionable (too high), mainly because its per-capita calorie-supply estimate for this particular region is more downward biased than elsewhere (cf. section V.D).

(Table 7 about here)

The estimated shares of young children and adult women who are wasted, as reported in Table 7, are averages for a large number of representative sample populations in respective region (there are a few exceptions that we will return to 
below). Most of these estimated averages are completely at odds with the POU estimates from the FAO. The estimated shares of children below the weight-forheight norm are 3 to 17 per cent in the five regions (column 3), all notably lower than the estimates of POU. The shares of adult women with a $\mathrm{BMI}<18.5$ are also considerably lower than the POU estimates for most of the regions. Only for South Asia, where more than half the women are below the BMI norm, the opposite holds. The exceptionally poor anthropometric status of women in South Asia as compared to the other regions has yet to be convincingly explained. ${ }^{52}$

\section{What Explains the Incongruity?}

The observation that the POU estimates are considerably higher than the estimated shares of wasted children and adult women in almost all the regions has two possible explanations. The first is that at least one set of estimates is biased. The other is that the two measurement approaches are non-comparable in some way.

We have previously argued that the POU estimates from the FAO are generally upward biased. The anthropometric estimates are reliable in the sense that they are obtained with small measurement errors and biases. ${ }^{53}$ Moreover, the estimates for young children are based on sufficiently large and numerous samples to ensure that they are representative for respective region. The latter also holds for the estimates of adult women in some of the regions (but not East \& Southeast Asia and the Middle East \& North Africa; see note b in Table 7). There is thus little reason to think that the anthropometric indicators are generally biased or non-representative.

There are problems with comparability, however. First, the comparison between the POU estimates and the shares of wasted children is distorted by the fact that different weight norms for young children have been used. In deriving its calorie-cut-off points, the FAO uses the median value of weight-for-age range in a US reference population as the norm for children. The weight-for-age norms used in the anthropometric assessments are 2 standard deviations below the median values, or about 15-20 per cent lower. Had the FAO used the anthropometric weight norms for children, their calorie cut-off-points (cet par) would have been somewhat smaller and the estimated POU between 2 and 10 percentage points 
lower in the various regions. ${ }^{54}$ It would still be difficult to reconcile revised POU estimates of these orders with the incidence of child wasting, especially in SubSaharan Africa and Latin America.

The discrepancy between the POU estimates from the FAO and the estimated shares of wasted adult women is unrelated to body-weight norms. The POU estimates — as we have seen in section III above — and the direct anthropometric estimates are derived from exactly the same weight norm for adults $(\mathrm{BMI}=18.5)$. It is hence notable that the "indirect" FAO estimates of the share of the population with weight failure, are almost four times higher than the direct anthropometric estimates of the share of wasted adult women in SubSaharan Africa and Latin America \& Caribbean. ${ }^{55}$

There are, however, two other complications that have to be addressed. One is that there are no anthropometric estimates for adult men. The conventional view is that women are the chief victims of undernutrition. Hence, the anthropometric indicators for the two sexes combined ought to be lower than for women alone. If so, the gap between the POU estimates and incidence of adult wasting would be even larger when also men are included. ${ }^{56}$

The other complication is that anthropometric assessments of body weight reveal nothing about the physical activity that people exert. The calorie-cut-off points behind the POU estimates, as we have seen, allow for the energy expenditure for light physical activity. It may hence be that the great majority of adult women in Sub-Saharan Africa and Latin America have a calorie intake sufficient to have body weights above the anthropometric norm, but not to expend enough energy in work and other physical activities to stay healthy. Considering that the estimated work-force participation rates for women (mainly in agriculture) in these two regions are comparatively high, ${ }^{57}$ the probability that physical inactivity is a main explanation for the discrepancy between the indirect (POU) and direct estimates of women weight failure seems low.

All in all, the observation that the anthropometric indicators of the prevalence of wasting among young children and adult women are generally much lower than the POU estimates from the FAO is not the definitive proof that the latter are upward biased. There are, as discussed above, unresolved issues concerning comparability. What we can ascertain for sure, however, is that the 
direction in the discrepancies does not contradict our earlier conclusion that the FAO has generally overestimated the prevalence of undernutrition. The anthropometric estimates are also in general more in line with the alternative POU estimates derived here (table 6, panel B).

\section{Summary and Conclusions}

The estimates of the prevalence of undernutrition in the world from the FAO form the empirical basis for the recent initiative to reduce the number of undernourished people by half before the year 2015. These estimates are derived from a model that has an in-built bias, which has been pointed out since long ${ }^{58}$, the use of which the FAO justifies by lack of crucial data. The first contribution in this paper is the demonstration that the FAO has, de facto, assigned a number to the critical "missing" parameter when constructing its cut-off points. It was further shown that with a number on this parameter, the FAO could have used the alternative, joint-distribution, estimation method, which produce "unbiased" estimates of POU (since the second missing parameter turns out to be of minuscule quantitative importance). The application of this alternative model while still keeping with the FAO food-supply-based approach and basic data suggests a notably higher incidence of undernutrition than reported by the FAO. We were hence able to put numbers on the (downward) bias in the estimated POU in the world, induced by the estimation method used by the FAO ( see Table 3 ).

We also found reason to doubt most values of the key parameter that the FAO has inserted in its estimations, however. First, the FAO has failed to recognise that physiologists since the early 1990s have revised their estimates of $\mathrm{BMR} / \mathrm{kg}$ for people in the "tropics" downward by about 10 per cent. Second, the FAO has ignored the fact that household per-capita calorie requirement for BMR (and hence MPCCR) varies across households due to differences in size and age composition. Third, the FAO must have overestimated the variance in the calorieavailability distribution across households as the ensuing habitual intakes in the lower tail are impossibly low in living households. The POU was therefore reestimated with both the FAO and the alternative model, using other parameter values that square better with empirical observations and/or are more plausible. The estimated POU then fell drastically in most regions (see Table 6). 
Comparing the original POU estimates from the FAO with the revised ones, based on the alternative model and data, gives an indication of the net effect of the two biases in the POU estimates. That is, the underestimation induced by the use of the cut-off-point method and the overestimation due to inadequate data. This comparison indicates a relatively small net overestimation in Sub-Saharan Africa, but substantial overestimation in the other regions by the FAO (Table 6.B). The overall conclusion is hence that, on a net basis, the FAO has overestimated the POU in the world, although unevenly so, signifying that also the comparability across regions (and presumably individual countries) has been compromised. The revised POU estimates are also more compatible with anthropometric indicators for most regions, which further strengthen the notion that the FAO estimates are generally too high.

The revised POU estimates must nevertheless be interpreted cautiously. One reason is that the (uniform) alternative values attached to the two distribution parameters $\left(\mathrm{CV}_{\mathrm{y}}\right.$ and $\left.\mathrm{CV}_{\mathrm{x}}\right)$ are not sufficiently well founded empirically. Moreover, for the lack of alternative data, we have used the FAO national percapita calorie availability estimates $\left(\mu_{\mathrm{y}}\right)$. These estimates contain large margins of error, it is widely agreed. However, if the FAO calorie supply estimates are systematically biased, it is on the downward side, especially in Sub-Saharan Africa $^{59}$. In that case, also the revised POU estimates reported in Table 6 are on the high side.

What the above exercises demonstrate is, above all, that the POU estimates provided by FAO are much too unreliable for directing policy in any meaningful way, or for simply providing an acceptably accurate "map" of the prevalence of undernutrition in various parts of the world. The main contribution of this article is hence not the particular revised estimates of POU that have been derived. The main contributions are the demonstrations of (1) how sensitive the POU estimates are to the choice of (a biased) estimation model; (2) how brittle or unsubstantiated the empirical bases are for key parameter values; and (3) how fragile the estimated POU is for slight variations in these uncertain parameter values (irrespective of estimation method).

By undertaking the numerical exercises, we have also shed light on what has to be done in order to improve the estimation method and data collection. First, 
the FAO has to replace the present calorie-cut-off-point model, which is inherently biased, with the joint-distribution model. Second, the FAO has to start collecting more complete and reliable data on the key parameters in that model. The least costly and time-consuming improvements would be to lower the BMR estimates in accordance with recent findings and to undertake estimates of interhousehold variance in MPCCR due to differences in age structure and size. To improve the estimates of national food (calorie) supplies and their distribution over households would be more costly and take longer time.

If the objective to reduce by half the absolute number of undernourished people in the world before the year 2015 is taken seriously, and new policies are to be initiated, the international community simply must have more detailed and reliable information on where the undernourished are, who they are, and how many they are. ${ }^{60}$ Reliable indicators of undernutrition are not needed only for directing and designing interventions, however. Equally important, we need accurate measurements if we shall be able to find out to what extent undernutrition at the level of countries affects economic growth and poverty reduction negatively. If it can be convincingly demonstrated that undernutrition like poor health and low educational attainment - is a significant and independent barrier to growth in poor countries, it may become easier to mobilise political (financial) support for its alleviation than if motivated on humanitarian grounds only. 
TABLE 1

DERIVATION OF THE IMPLICIT COEFFICIENT OF VARIATION IN INTER-HOUSEHOLD PERCapita Calorie Requirement Distribution $\left(\mathrm{CV}_{\mathrm{X}}\right)$ Used in the FAO Estimates of POU, BY MAJOR GEOGRAPHICAL REGIONS, IN 1990/92

\begin{tabular}{|l|c|c|c|c|c|}
\hline & $\begin{array}{l}\text { Average } \\
\text { calorie re- } \\
\text { quirement }\end{array}$ & $\begin{array}{l}\text { Minimum } \\
\text { calorie re- } \\
\text { quirement }^{\mathrm{a}}\end{array}$ & $\begin{array}{l}\text { Two } \\
\text { standard } \\
\text { deviation }\end{array}$ & $\begin{array}{l}\text { One } \\
\text { standard } \\
\text { deviation }\end{array}$ & $\begin{array}{l}\text { Coeffi- } \\
\text { cient of } \\
\text { variation }\end{array}$ \\
\hline Region & $\mu_{\mathrm{x}}$ & $\delta_{\mathrm{x}}$ & $2 \sigma_{\mathrm{x}}$ & $\sigma_{\mathrm{x}}$ & $\mathrm{CV}_{\mathrm{x}}$ \\
\hline Sub-Saharan Africa & $(1)$ & $(2)$ & $(3)=$ & $(4)=$ & $(5)=$ \\
$(1)-(2)$ & $1 / 2(3)$ & $(4) /(1)^{\mathrm{b}}$ \\
\hline Near East \& North Africa & 2,150 & 1,840 & 310 & 155 & 0.075 \\
\hline East \& Southeast Asia & 2,220 & 1,880 & 340 & 170 & 0.075 \\
\hline South Asia & 2,110 & 1,790 & 320 & 160 & 0.075 \\
\hline Latin America \& Caribbean & 2,200 & 1,870 & 330 & 165 & 0.075 \\
\hline
\end{tabular}

SourCE.- Columns (1) and (2) are from FAO, The $6^{\text {th }}$ World Food Survey (Rome, 1996:

Table 16).

NOTES.-a) Number of calories per-capita and day for households; b) Dividing column (4) with column (1) gives $\mathrm{CV}_{\mathrm{x}}$ 's that differ on the third decimal points because the FAO has rounded off the values of $\mu_{\mathrm{x}}$ and $\delta_{\mathrm{x}}$ to even 10-numbers. A quick check reveals that "imagined" non-rounded numbers attached to these two entities, are consistent with a uniform $\mathrm{CV}_{\mathrm{x}}$ of 0.075 for all five regions. 
TABLE 2

RoBUSTNESS TEST OF UNBIASED EsTIMATES OF POU TO VARIATION IN THE CORRELATION Coefficient, By Major GeographicAl Regions, in 1990/92 (PER CENT)

\begin{tabular}{|l|c|c|c|c|c|c|c|}
\hline & \multicolumn{7}{|c|}{ Assumed Range of Correlation Coefficient $(\rho)$} \\
\hline & 0.00 & 0.40 & 0.50 & 0.60 & 0.70 & 0.80 & 0.90 \\
\hline Region & $(1)$ & $(2)$ & $(3)$ & $(4)$ & $(5)$ & $(6)$ & $(7)$ \\
\hline & \multicolumn{7}{|c|}{ Estimated Prevalence of Undernutrition (per cent) } \\
\hline & 56 & 57 & 57 & 57 & 57 & 58 & 58 \\
\hline Sub-Saharan Africa ${ }^{\text {a) }}$ & 27 & 25 & 24 & 24 & 23 & 22 & 21 \\
\hline Near East \& North Africa & 36 & 35 & 34 & 33 & 33 & 32 & 31 \\
\hline East \& Southeast Asia & 46 & 46 & 46 & 46 & 46 & 45 & 45 \\
\hline South Asia & 34 & 32 & 32 & 31 & 31 & 30 & 29 \\
\hline Latin America \& Caribbean & & & & & & & \\
\hline
\end{tabular}

SOURCE.-Estimates based on the joint-distribution method and FAO data (see text).

NOTE. - a) It should be noted that when $\rho$ assumes increasingly higher values, the estimated POU for the Sub-Saharan African region increases marginally, but declines in the other four regions. The reason for this is that for Sub-Saharan Africa, the FAO estimates of per-capita availability of calories is below the estimated average per-capita calorie requirement $\left(\mu_{\mathrm{y}}<\mu_{\mathrm{x}}\right)$, while the opposite holds in the other regions (see Table 5 below). 
TABLE 3

COMPARISON BETWEEN FAO AND “UNBIASED” ESTIMATES OF POU, BY MAJOR Geographical Regions, in 1990/92 (Per CENT)

\begin{tabular}{|l|c|c|c|c|c|}
\hline & \multicolumn{2}{|l|}{$\begin{array}{l}\text { Estimates based on } \\
\text { FAO calorie norms } \\
(\mathrm{a}+\mathrm{c} \text { in Figure 1) }\end{array}$} & $\begin{array}{l}\text { Unbiased } \\
\text { estimates } \\
(\mathrm{b}+\mathrm{c})\end{array}$ & \multicolumn{2}{l|}{$\begin{array}{l}\text { Percentage Point } \\
\text { Bias }\end{array}$} \\
\hline Region & $(1)$ & $(2)$ & $(3)$ & $\begin{array}{c}(4)= \\
(1)-(3)\end{array}$ & $\begin{array}{c}(5)= \\
(2)-(3)\end{array}$ \\
\hline Sub-Saharan Africa & 43 & 43 & 57 & -14 & -14 \\
\hline Near East \& North Africa & 12 & 17 & 23 & -11 & -6 \\
\hline East \& Southeast Asia & 16 & 22 & 33 & -17 & -11 \\
\hline South Asia & 22 & 32 & 46 & -24 & -14 \\
\hline Latin America \& Caribbean & 15 & 21 & 31 & -16 & -10 \\
\hline
\end{tabular}

SOURCES.-The numbers in column (1) are from the FAO, The $6^{\text {th }}$ World Food Survey (Rome, 1996: Table 14). The numbers in column (2) were obtained when POU was reestimated with the FAO method (see text). The numbers in column (3) are from Table 2 above (for $\rho=0.70$ ). 
TABLE 4

EXAMPLES OF ESTIMATED PER-CAPITA CALORIE REQUIREMENT FOR BMR AND MPCCR FOR Households of DifFERENT Size AND Age COMPOSITION

\begin{tabular}{|c|c|c|c|c|c|c|c|c|}
\hline \multirow{3}{*}{$\begin{array}{l}\text { Composition of } \\
\text { household }\end{array}$} & \multicolumn{6}{|c|}{ BMR of individuals ${ }^{a}$} & \multirow{3}{*}{$\begin{array}{l}\text { BMR/ } \\
\text { capita } \\
\text { FAO } \\
\text { Alt. }^{\mathrm{e})}\end{array}$} & \multirow{3}{*}{$\begin{array}{l}\mathrm{MPCCR}^{\mathrm{d})} \\
\text { Alt. }^{\mathrm{e})}\end{array}$} \\
\hline & \multicolumn{2}{|c|}{ No. Adults ${ }^{b)}$} & \multicolumn{4}{|c|}{ No. Children $^{\text {c) }}$} & & \\
\hline & 1 & 2 & 1 & 2 & 3 & 4 & & \\
\hline $\begin{array}{l}\text { A. One adult and two } \\
\text { children aged } 1 \text { and } 4\end{array}$ & 1330 & - & 430 & 850 & - & - & $\begin{array}{l}870 \\
785\end{array}$ & $\begin{array}{l}1350 \\
1215\end{array}$ \\
\hline $\begin{array}{l}\text { B. Two adults and two } \\
\text { children aged } 1 \text { and } 4\end{array}$ & 1330 & 1330 & 430 & 850 & - & - & $\begin{array}{l}985 \\
885\end{array}$ & $\begin{array}{l}1535 \\
1380\end{array}$ \\
\hline $\begin{array}{l}\text { C. One adult and four } \\
\text { children aged } 1,4,7,10\end{array}$ & 1330 & - & 430 & 850 & 980 & 1170 & $\begin{array}{l}950 \\
855\end{array}$ & $\begin{array}{l}1485 \\
1335\end{array}$ \\
\hline $\begin{array}{l}\text { D. Two adults and four } \\
\text { children aged } 1,4,7,10\end{array}$ & 1330 & 1330 & 430 & 850 & 980 & 1170 & $\begin{array}{l}1015 \\
915\end{array}$ & $\begin{array}{l}1585 \\
1425\end{array}$ \\
\hline .. & & & & & & & & \\
\hline $\begin{array}{l}\text { M. Two adults and four } \\
\text { children/adolescents } \\
\text { aged } 10,13,16,19\end{array}$ & 1330 & 1330 & 1170 & 1350 & 1420 & 1460 & $\begin{array}{l}1345 \\
1210\end{array}$ & $\begin{array}{l}2095 \\
1885\end{array}$ \\
\hline
\end{tabular}

SOURCE.-All base data on BMR/kilo of body weight are from FAO/WHO/UNU, Energy and Protein Requirements (Technical Report Series, 724, WHO, Geneva, 1985), as replicated in Appendix Table 3.

Notes.-a) Average for males and females; b) The BMR for adults has been calculated from a BMI = 18.5 for a given height of $168 / 157 \mathrm{~cm}$ for males/females; c) The BMR for children below the age of 10 has been derived from normal body weights in reference population and the BMR for adolescents has been derived from a BMI $=18.5$ and heights equal to normal height for age in the reference population; d) MPCCR $=1.56$ times BMR/capita; e) The number in italics in this column are 90 per cent of the values derived on the basis of FAO/WHO/UNU (1985, ibid.) data. 
TABLE 5

Estimated LOWER BOUND PER-CAPITA CALORIE AVAILABILITY AND MPCCR FOR DifFerent Combinations of Parameter Values, By Major Geographical Regions, IN 1990/92

\begin{tabular}{|c|c|c|c|c|}
\hline & & \multicolumn{3}{|c|}{ A. Per-capita calorie availability in low tail } \\
\hline & $\mu_{\mathrm{y}}$ & \multicolumn{3}{|c|}{$\mathrm{CV}_{\mathrm{y}}$} \\
\hline \multirow[t]{2}{*}{ Region } & & 0.30 & 0.25 & 0.20 \\
\hline & & $(1)^{a)}$ & $(2)^{a)}$ & $(3)^{a)}$ \\
\hline Sub-Saharan Africa & 2,040 & 820 & 1,020 & 1,225 \\
\hline Near East \& North Africa & 2,960 & 1,185 & 1,480 & 1,775 \\
\hline East \& Southeast Asia & 2,680 & 1,070 & 1,340 & 1,610 \\
\hline South Asia & 2,290 & 920 & 1,145 & 1,375 \\
\hline \multirow[t]{3}{*}{ Latin America \& Caribbean } & 2,740 & 1,150 & 1,370 & 1,645 \\
\hline & & \multicolumn{3}{|c|}{$\begin{array}{l}\text { B. Minimum per-capita calorie requirement } \\
\text { (MPCCR) in low tail }\end{array}$} \\
\hline & $\mu_{\mathrm{x}}$ & \multicolumn{3}{|c|}{$\mathrm{CV}_{\mathrm{x}}$} \\
\hline \multirow[t]{2}{*}{ Region } & & 0.075 & 0.125 & 0.15 \\
\hline & & $(1)^{b)}$ & $(2)^{c)}$ & $(3)^{c)}$ \\
\hline Sub-Saharan Africa & 2,100 & 1,800 & 1,420 & 1,325 \\
\hline Near East \& North Africa & 2,150 & 1,840 & 1,450 & 1,355 \\
\hline East \& Southeast Asia & 2,220 & 1,880 & 1,500 & 1,400 \\
\hline South Asia & 2,110 & 1,790 & 1,425 & 1,330 \\
\hline Latin America \& Caribbean & 2,220 & 1,870 & 1,485 & 1,385 \\
\hline
\end{tabular}

SOURCE.-Data for $\mu_{\mathrm{y}}$ and $\mu_{\mathrm{x}}$ are from FAO, The $6^{\text {th }}$ World Food Survey (Rome, 1996: Tables 1 and 16).

Notes. $-\mathrm{a})$ The estimates in this column are derived as $\mu_{\mathrm{y}}\left(1-2 \mathrm{CV}_{\mathrm{y}}\right)$; b) The estimates in this column are from the FAO ( $c f$. Table 1$)$ and are derived as $\mu_{\mathrm{x}}\left(1-2 \mathrm{CV}_{\mathrm{x}}\right)$; c) The estimates in this column are derived as $0.90 \mu_{\mathrm{x}}\left(1-2 \mathrm{CV}_{\mathrm{x}}\right)$. 
TABLE 6

ESTIMATEd POU with Alternative Methods AND COMBINATIONS OF PARAMETER VALUES, By MAJOR GEOGRAPHICAL REGIONS, IN 1990/92

\begin{tabular}{|c|c|c|c|c|}
\hline & \multirow{3}{*}{$\frac{\text { Parameters }}{\mathrm{CV}_{\mathrm{y}}}$} & \multicolumn{3}{|c|}{ Combination of Parameter Values } \\
\hline & & FAO & \multicolumn{2}{|l|}{ Alternative } \\
\hline & & $\approx 0.30$ & 0.25 & 0.20 \\
\hline & $\mathrm{CV}_{\mathrm{x}}$ & 0.075 & 0.125 & 0.15 \\
\hline & $\mu_{\mathrm{x}}{ }^{\mathrm{a})}$ & 1.00 & 0.90 & 0.90 \\
\hline \multicolumn{2}{|l|}{ Region } & (1) & (2) & (3) \\
\hline & & \multicolumn{3}{|c|}{ A. Estimated POU with FAO method (per cent) ${ }^{\text {b) }}$} \\
\hline \multicolumn{2}{|l|}{ Sub-Saharan Africa } & 43 & 14 & 9 \\
\hline \multicolumn{2}{|l|}{ Near East \& North Africa } & 17 & 2 & 1 \\
\hline \multicolumn{2}{|l|}{ East \& Southeast Asia } & 22 & 5 & 2 \\
\hline \multicolumn{2}{|l|}{ South Asia } & 32 & 8 & 4 \\
\hline \multicolumn{2}{|c|}{ Latin America \& Caribbean } & 21 & 4 & 1 \\
\hline & & \multicolumn{3}{|c|}{$\begin{array}{l}\text { B. Estimated POU with joint-probability method } \\
\left(\text { per cent) }{ }^{\text {b) }}\right.\end{array}$} \\
\hline \multicolumn{2}{|l|}{ Sub-Saharan Africa } & 57 & 42 & 38 \\
\hline \multicolumn{2}{|l|}{ Near East \& North Africa } & 23 & 7 & 3 \\
\hline \multicolumn{2}{|l|}{ East \& Southeast Asia } & 33 & 16 & 9 \\
\hline \multicolumn{2}{|l|}{ South Asia } & 46 & 28 & 20 \\
\hline \multicolumn{2}{|c|}{ Latin America \& Caribbean } & 31 & 14 & 7 \\
\hline
\end{tabular}

SOURCE.-Author's calculations as explained in the text and in the below notes.

NOTES.-a) The number 0.90 on this row means that this parameter has been assigned a value 90 per cent of the FAO value; b) All estimates in this panel are derived on data for regional averages, as reported in Table 3, column 2 above. 
TABLE 7

CONTRAsting POU Estimates With SHARES OF the PopUlation BELOW ANTHROPOMetric Norms (Per CENT), By Major GeOgRaphical Regions, EARLy 1990S

\begin{tabular}{|l|c|c|c|c|}
\hline & A. POU estimates & \multicolumn{3}{|c|}{ B. Anthropometric status } \\
\hline \multirow{2}{*}{ Region } & $\begin{array}{l}\text { FAO method and } \\
\text { parameters }\end{array}$ & \multicolumn{2}{|l|}{ Pre-School Children } & $\begin{array}{c}\text { Adult } \\
\text { Women }\end{array}$ \\
\cline { 2 - 5 } & & $\begin{array}{c}\mathrm{H} / \mathrm{A}< \\
-2 \mathrm{sd}^{\text {a) }}\end{array}$ & $\begin{array}{c}\mathrm{W} / \mathrm{H}< \\
-2 \mathrm{sd}^{\text {a) }}\end{array}$ & $\begin{array}{c}\text { BMI } \\
18.5^{\text {b) }}\end{array}$ \\
\hline Sub-Saharan Africa & $(1)$ & $(2)$ & $(3)$ & $(4)$ \\
\hline Near East \& North Africa & 43 & 38 & 7 & 11 \\
\hline East \& Southeast Asia & 17 & 32 & 9 & 2 \\
\hline South Asia & 22 & 33 & 5 & 16 \\
\hline Latin America \& Caribbean & 21 & 60 & 17 & 52 \\
\hline
\end{tabular}

SOURCES.-The estimates in column (1) are taken from Table 6 above and derived on data for regional averages. The estimates in columns (2) and (3) are from the WHO, Global Data Base on Child Growth (Geneva, 2000) as replicated by the FAO, The 6th World Food Survey (1996: Table 21). The estimates in column (4) are mainly from ACC/SCN, Fourth Report on the World Nutrition Situation (Geneva, 2000: Table 1.8); and M. Nube, "Confronting Dietary Energy Supply with Anthropometry in the Assessment of Undernutrition Prevalence at the Level of Countries," World Development, 29 (2001). Both are based on data from Demographic and Health Surveys produced by Macroint (Washington D.C.: Macro International, 1999, /www.macroint.com/dhs/).

NOTES.-a) Nationally representative estimates of the share of children with weight-forheight and height-for-age below the norms are available for most countries in all the regions; b) Estimates of adult women with a $\mathrm{BMI}<18.5$ are available for one country only in the Near East \& North Africa (Egypt) and two countries in East \& Southeast Asia (China and Indonesia), which is not enough to ensure acceptable representativity. The estimates for Sub-Saharan Africa, South Asia and Latin America \& Caribbean cover most countries in respective region. 


\section{Appendix 1: End Tables}

END TABLE 1

Derivation of the Minimum Body Weight And Physical Activity Level Allowed FOR BY THE FAO IN ESTIMATING CALORIE CUT-OFF POINTS WORLD-WIDE ${ }^{\text {a) }}$

\begin{tabular}{|l|c|c|c|c|c|c|}
\hline & \multicolumn{3}{|c|}{ Males (m) } & \multicolumn{3}{c|}{ Females (f) } \\
\hline & Aver. & Min. & CV & Aver. & Min. & CV \\
\hline & $(1)$ & $(2)$ & $(3)$ & $(4)$ & $(5)$ & $(6)$ \\
\hline & & & & & & \\
\hline A. Body Mass Index (BMI) & 22.0 & 18.5 & 0.080 & 22.0 & 18.5 & 0.080 \\
\hline \multicolumn{7}{|l|}{} \\
\hline B. Daily Activities (PAL) & & & & & & \\
\hline 1. Sleep 8 hours & 1.00 & 1.00 & 0 & 1.00 & 1.00 & 0 \\
\hline 2. Low-active 8 hours ${ }^{\text {b) }}$ & 1.40 & 1.40 & 0 & 1.40 & 1.40 & 0 \\
\hline 3. Work activity 8 hours & 3.00 & 2.53 & 0.078 & 2.83 & 2.57 & 0.046 \\
\hline $\begin{array}{l}\text { 4. Average activity 24 } \\
\text { hours }\end{array}$ & 1.78 & 1.55 & 0.065 & 1.64 & 1.56 & 0.024 \\
\hline
\end{tabular}

SOURCE.-FAO, The $6^{\text {th }}$ World Food Survey (Rome, 1996: Table 1, p. 131) and author's calculations (CVs and B. rows 2 and 3).

NOTES.-a) By multiplying the BMR for each age and sex category by the PAL multiple, and aggregating, the FAO derives the estimated minimum calorie requirement (the CCOP); b) Details on rows 2 and 3 may differ slightly from the numbers actually used (but not published) by the FAO in deriving the numbers on row 4 . 
END TABLE 2

Robustness Test of Estimated POU with the JoInt-Distribution Method AND Alternative Combinations of PARAmeter VALUes

\begin{tabular}{|c|c|c|c|c|c|c|}
\hline & Parameter & \multicolumn{5}{|c|}{ Combination of Parameter Values } \\
\hline & $\mathrm{CV}_{\mathrm{y}}$ & 0.30 & 0.25 & 0.25 & 0.20 & 0.20 \\
\hline & $\mathrm{CV}_{\mathrm{x}}$ & 0.075 & 0.125 & 0.15 & 0.125 & 0.15 \\
\hline & $\mu_{\mathrm{x}}{ }^{\mathrm{a})}$ & 1.00 & 0.90 & 0.90 & 0.90 & 0.90 \\
\hline \multirow[t]{2}{*}{ Region } & & $(1)$ & $(2)$ & (3) & $(4)$ & $(5)$ \\
\hline & & \multicolumn{5}{|c|}{ A. Estimated POU (per cent) for $\rho=0.50$} \\
\hline \multicolumn{2}{|l|}{ Sub-Saharan Africa } & 57 & 43 & 43 & 40 & 40 \\
\hline \multicolumn{2}{|l|}{ Near East \& North Africa } & 24 & 11 & 11 & 6 & 6 \\
\hline \multicolumn{2}{|l|}{ East \& Southeast Asia } & 34 & 20 & 20 & 14 & 15 \\
\hline \multicolumn{2}{|l|}{ South Asia } & 46 & 31 & 30 & 25 & 26 \\
\hline \multicolumn{2}{|l|}{ Latin America \& Caribbean } & 32 & 18 & 17 & 12 & 12 \\
\hline & & \multicolumn{5}{|c|}{ B. Estimated POU (per cent) for $\rho=0.70$} \\
\hline \multicolumn{2}{|l|}{ Sub-Saharan Africa } & 57 & 42 & 42 & 38 & 38 \\
\hline \multicolumn{2}{|l|}{ Near East \& North Africa } & 23 & 7 & 7 & 3 & 3 \\
\hline \multicolumn{2}{|l|}{ East \& Southeast Asia } & 33 & 16 & 15 & 10 & 9 \\
\hline \multicolumn{2}{|l|}{ South Asia } & 46 & 28 & 27 & 21 & 20 \\
\hline \multicolumn{2}{|l|}{ Latin America \& Caribbean } & 31 & 14 & 13 & 7 & 7 \\
\hline & & \multicolumn{5}{|c|}{ C. Estimated POU (per cent) for $\rho=0.90$} \\
\hline \multicolumn{2}{|l|}{ Sub-Saharan Africa } & 58 & 40 & 38 & 34 & 31 \\
\hline \multicolumn{2}{|l|}{ Near East \& North Africa } & 21 & 3 & 2 & 0 & 0 \\
\hline \multicolumn{2}{|l|}{ East \& Southeast Asia } & 31 & 11 & 8 & 3 & 2 \\
\hline \multicolumn{2}{|l|}{ South Asia } & 45 & 23 & 20 & 13 & 10 \\
\hline \multicolumn{2}{|l|}{ Latin America \& Caribbean } & 29 & 8 & 6 & 2 & 1 \\
\hline
\end{tabular}

SOURCE.-Estimates in column (1) are from the FAO, The $6^{\text {th }}$ World Food Survey (Rome, 1996); estimates in the other columns are derived as explained in text on the basis of equation (1) and data for regional averages (see Table 3 above).

NOTE. - a) The number 0.90 on this row means that this parameter has been assigned a value which is 90 per cent of FAO value. 
END TABLE 3

ESTIMATED BMR IN INDIVIDUALS, BY SEX AND AGE

\begin{tabular}{|c|c|c|c|c|c|c|c|c|}
\hline & \multicolumn{4}{|c|}{ Males (m) } & \multicolumn{4}{|c|}{ Females (f) } \\
\hline $\begin{array}{l}\text { Age range } \\
\text { (years) }\end{array}$ & $\begin{array}{l}\text { Height } \\
(\mathrm{cm})\end{array}$ & $\begin{array}{l}\text { Norm } \\
\text { weight } \\
\text { (kilos) }\end{array}$ & $\begin{array}{l}\text { BMR/ } \\
\text { kilo/ } \\
\text { day }\end{array}$ & $\begin{array}{l}\text { Total } \\
\text { BMR/ } \\
\text { day }\end{array}$ & $\begin{array}{l}\text { Height } \\
(\mathrm{cm})\end{array}$ & $\begin{array}{l}\text { Norm } \\
\text { weight } \\
\text { (kilos) }\end{array}$ & $\begin{array}{l}\text { BMR/ } \\
\text { kilo/ } \\
\text { day }\end{array}$ & $\begin{array}{l}\text { Total } \\
\text { BMR/ } \\
\text { day }\end{array}$ \\
\hline (1) & (2) & (3) & (4) & (5) & (6) & (7) & (8) & (9) \\
\hline $0-1$ & 67 & 8 & 57 & 460 & 65 & 7 & 57 & 400 \\
\hline $1-2$ & 82 & 12 & 57 & 680 & 81 & 11 & 56 & 620 \\
\hline $2-3$ & 94 & 14 & 57 & 800 & 91 & 13 & 57 & 740 \\
\hline $3-4$ & 99 & 16 & 54 & 860 & 98 & 15 & 56 & 840 \\
\hline $4-5$ & 106 & 18 & 50 & 900 & 106 & 17 & 52 & 880 \\
\hline Aver. $m / f$ & & & & & & & & 720 \\
\hline $5-6$ & 113 & 20 & 48 & 960 & 112 & 19 & 49 & 930 \\
\hline $6-7$ & 119 & 22 & 45 & 990 & 118 & 21 & 46 & 970 \\
\hline $7-8$ & 124 & 24 & 43 & 1,030 & 124 & 23 & 44 & 1,010 \\
\hline $8-9$ & 129 & 27 & 41 & 1,110 & 129 & 27 & 41 & 1,110 \\
\hline $9-10$ & 135 & 30 & 39 & 1,170 & 135 & 30 & 39 & 1,170 \\
\hline Aver. $m / f$ & & & & & & & & 1,045 \\
\hline $10-11$ & 140 & 36 & 38 & 1,370 & 142 & 37 & 34 & 1,260 \\
\hline $11-12$ & 147 & 40 & 35 & 1,400 & 148 & 41 & 32 & 1,310 \\
\hline $12-13$ & 153 & 43 & 33 & 1,420 & 155 & 44 & 29 & 1,280 \\
\hline $13-14$ & 160 & 47 & 31 & 1,460 & 159 & 47 & 28 & 1,320 \\
\hline $14-15$ & 166 & 51 & 30 & 1,530 & 161 & 48 & 27 & 1,300 \\
\hline Aver. $m / f$ & & & & & & & & 1,365 \\
\hline $15-16$ & 171 & 54 & 29 & 1,570 & 162 & 49 & 26 & 1,270 \\
\hline 16-17 & 175 & 57 & 28 & 1,600 & 163 & 49 & 26 & 1,270 \\
\hline $17-19$ & 177 & 58 & 28 & 1,620 & 164 & 50 & 26 & 1,300 \\
\hline Aver. $m / f$ & & & & & & & & 1,450 \\
\hline $20-60$ & 168 & 52 & 28 & 1,460 & 157 & 46 & 26 & 1,200 \\
\hline Aver. $m / f$ & & & & & & & & 1,330 \\
\hline$>60$ & 166 & 51 & 23 & 1,170 & 155 & 45 & 24 & 1,080 \\
\hline Aver. $m / f$ & & & & & & & & 1,125 \\
\hline
\end{tabular}

SOURCES.-BMR/kg data are from FAO/WHO/UNU, Energy and Protein Requirements (Technical Report Series, 724, WHO, Geneva, 1985), and height-for-age and weight data are from. L. S. Stephenson et al., A Comparison of Growth Standards (Monograph Series 12, Cornell University, Ithaca, New York State, 1983) and H. W. Jürgens et al., 
International Data on Anthropometry, Occupational Safety and Health Series, 65 (International Labour Organisation, Geneva, 1990). 


\title{
Appendix 2: Abbreviations
}

\author{
$\mathrm{BMI}=$ Body Mass Index \\ BMR $=$ Basal Metabolic Rate \\ CCOP $=$ Calorie Cut-off Point \\ MPCCR $=$ Minimum Per-capita Calorie Requirement \\ PAL $=$ Physical Activity Level \\ POU $=$ Prevalence of Undernutrition
}




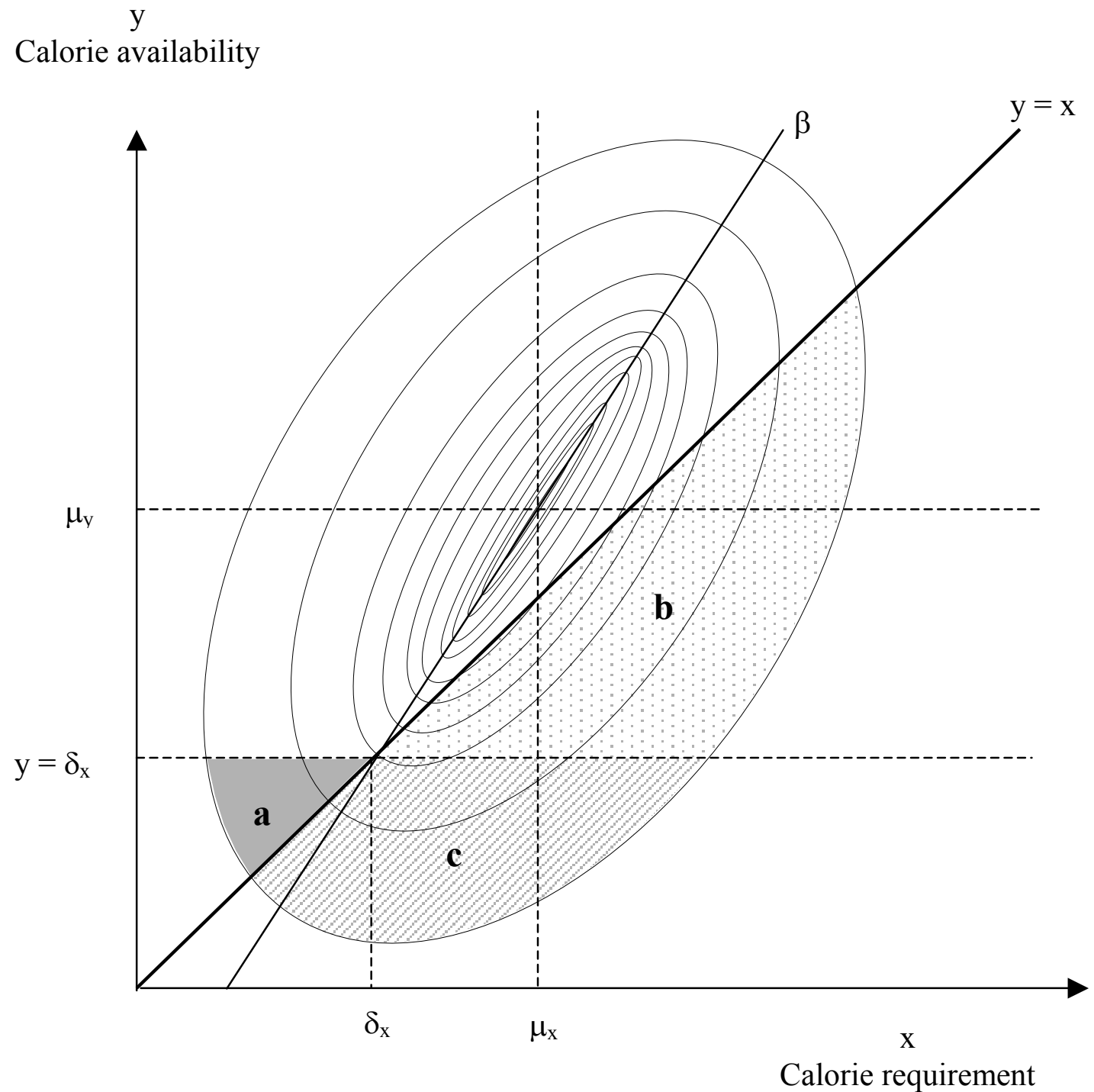

Fig. 1- Joint distribution of per-capita calorie intake and minimum calorie requirement in a population 
* Acknowledgement: Sincere thanks to Thomas Eisensee for competent research assistance, to Astrid Wåke for editorial help and to Sida for financial support. Comments in writings from L. Naiken, chief statistician at the FAO, on an earlier draft were highly appreciated, although disagreement prevails on some points. I am further indebted to an anonymous referee and to the Editor for constructive comments that improved the paper considerably. Comments from Judit McGuire and Stineke Oenema helped clarify the section on anthropometrics. All remaining errors are the sole responsibility of the author.

** A. K. Sen, "Foreword," in Poverty and Undernutrition: Theory, Measurement, and Policy, by P. Svedberg (Oxford: Oxford University Press, 2000).

1. See, e.g., J. R. Behrman, "The Economic Rationale for Investing in Nutrition in Developing Countries," World Development, 21 (1993) and J. Strauss and D. Thomas, "Human Resources: Empirical Modelling of Household and Family Decisions," Handbook of Development Economics, vol. 3A, eds. J. R. Behrman and T. N. Srinivasan (Amsterdam: North Holland, 1996).

2. For empirical evidence, see D. L. Pelletier, "The Relationship between Child Anthropometry and Mortality in Developing Countries: Implications for Policy, Programs and Future Research," The Journal of Nutrition, 124 (supplement) (1994) and P. Svedberg, Poverty and Undernutrition: Theory, Measurement, and Policy (Oxford: Oxford University Press, 2000).

3. See S. R. Osmani, "Poverty and Nutrition in South Asia," Nutrition and Poverty, ACC/SCN Policy Paper 16 (ACC/SCN, Geneva, 1997); and N. S. Scrimshaw, "Nutrition and Health from Womb to Tomb," Nutrition Today, 31 (1996) for assessments of current knowledge about these consequences of chronic undernutrition in humans. There are by now a large number of empirical growth studies that have found various proxy variables for initial "human capital", mainly in terms of education, but also health, to be significantly and robustly correlated to economic growth in subsequent periods (see J. Temple, "The New Growth Evidence," Journal of Economic Literature, 37 (1999) and A. Bhargava, D. T. Jamison, J. L. Lau, and C. J. L. Murray, "Modelling the Effetcs of Health on Economic Growth," Journal of Health Economics, 20 (2001). For empirical results, based on crosscountry investigation, showing that economic growth leads to poverty alleviation, i.e. generally benefits also the poorest population strata, see D. Dollar and A. Kraay, "Growth is Good for the Poor" (manuscript, 2000, www.worldbank.org/research).

4. FAO, The $6^{\text {th }}$ World Food Survey (Rome, 1996); FAO, The State of Food Security in the World 1999 (Rome, 1999).

5. The terminology used by the FAO is confusing. In the introductory chapter of The 6th World Food Survey, the FAO (1996) maintains that its concern is 'food inadequacy'. On page 44, the FAO states that 'the terms 'inadequate food intake' and 'inadequate access to food' cannot be equated with undernutrition as tends to be done in popular discussions". However, on the next page, in Table 14, the proportion 'undernourished' is estimated. In subsequent tables and figures, the terms 'undernurishment' and 'food inadequacy' are used interchangeably with no explanations attached. The follow-up report, The State of Food Insecurity in the World 1999, adds to the confusion by making a distinction between undernutrition and undernourishment, the latter being the concern of the FAO, it is said. The definitions of the two concepts read almost non-distinctively, however. It could further be noted that Naiken, chief statistician at the FAO, uses the term "undernutrition" in the title of his article "On Certain Statistical Issues Arising from the Use of Energy Requirements in Estimating the Prevalence of Energy Inadequacy (Undernutrition)," Journal of Indian Social and Agricultural Statistics, 51 (1998). A draft for The 6th World Food Survey, carried the title "World Food Supplies and Prevalence of Chronic Undernutrition in Developing Regions as Assessed in 1992" (FAO 1992).

6. See FAO, Poster with data on "Percentage of population chronically undernourished in 98 developing countries (1990-92)" (Rome, 1997) and FAO 1999, ibid. 
7. The first attempt by the FAO to monitor progress towards the 2015 objective was published in 1999 (FAO 1999, ibid.). According to the FAO, the absolute number of "hungry people" has declined to 790 million by $1995 / 97$, or by some 50 million since the early 1990 s. The POU estimates for 1990/92 (and earlier) have at the same time been revised by a few percentage points. In this paper, we have taken the estimates from FAO $(1996$, ibid.) as the benchmark since not enough details on the base data from which the 1999 revised estimates were derived, have been published.

8. Using a slightly modified version of the FAO model and alternative values of key parameters, the World Bank (IBRD, Poverty and Hunger, Washington D.C., 1986) derived POU estimates for the years 1970 and 1980. The Bank estimates of POU turned out to be considerably higher than the FAO ones for the same years. In order to identify the reasons for this discrepancy, G. H. Beaton, "Energy in Human Nutrition: Perspectives and Problems," Nutrition Reviews, 41 (1983) made detailed re-calculations for four countries. He found that the main reason was the use of considerably higher calorie norms by the Bank, while the different assumptions regarding how the calories were distributed mattered less (also see L. Naiken "Comparison of the FAO and the World Bank Methodology for Estimating the Incidence of Undernutrition," FAO Quarterly Bulletin of Statistics, 1 (1988): iii for a response to these findings). S. Reutlinger and H. Alderman, "The Prevalence of Caloriedeficient Diets in Developing Countries," World Development, 8 (1980) the chief architects behind the IBRD study, also estimated the proportion of people with a "calorie-deficient" diet, based on an index "which measure the share of the population whose average calorie intake is below average requirements" (italics added). The use of a very high calorie norm (compared to the FAO) was probably the main reason why 65 per cent of the population (weighted average) in the 41 sample countries were found to be calorie deficient in the mid 1960s.

9 See P. Svedberg, "841 Million Undernourished?," World Development, 27 (1999), and P. Svedberg 2000, ibid.

10. P. V. Sukathme, "The World's Hunger and Future Needs in Food Supplies," Journal of the Royal Statistical Society A, 124 (1961). The term "unbiased" has been put within commas in order to underscore the limited and partial meaning of the term unbiased in this context, where the concern is the bias induced by the choice of estimation model (section IV below). There are biases also in the data used by the FAO to estimate of POU, to be discussed in section V. Later contributions include T. N. Srinivasan, "Malnutrition: Measurement and Policy Issues," Journal of Development Economics, 8 (1981); and the three contributions to S. R. Osmani, ed., Nutrition and Poverty (Oxford: Clarendon, 1992) by T. N. Srinivasan, "Undernutrition: Concepts, Measurements, and Policy Implications,"; S. Anand and J. C. Harris, "Issues in the Measurement of Undernutrition,"; and N. C. Kakwani, "Measuring Undernutrition with Variable Requirements."

11. L. Naiken 1998, ibid.: 113-114; L. Naiken, 1988, ibid. Also see FAO 1996, ibid.: 117.

12. The only study that has used the joint-distribution type of model for the estimation of the proportion undernourished is that by N. C. Kakwani (1992, ibid). He applied this model to household survey data for rural and urban India from 1970-71. Some interesting similarities and differences in methods, derivation of key parameters, and results, as compared to the present study, will be pointed out along the route. Both N. C. Kakwani and S. Reutlinger and H. Alderman 1980, ibid., further derived estimates of the depth of the calorie deficiency ("calorie gaps") in respective populations, making use of Sukhatme types of models; in this paper, we will not deal with the "gap" issue for the sake of space.

13. This graphic representation of the Sukhatme model is adopted from S. Anand and J. C. Harris 1992, ibid.

14. There is not much empirical evidence to lean on when assigning the property of the joint distribution (normal, log-normal or other). The FAO estimations are based on a log-normal distribution of calorie availability since "the log-normal distribution was found to outperform the other two distributions [the normal and the beta] in terms of the standard tests for 
goodness of fit" (FAO 1996, ibid.: 132). We will follow the FAO procedure in order to accomplish comparability, although the empirical basis for the FAO results has not been published and, hence, examined.

15. This result has been shown previously by, e.g., T. N. Srinivasan (1981), S. Anand and J. C. Harris (1992), N. C. Kakwani (1992) cited in n. 10 above.

16. FAO 1996, ibid.; FAO 1999, ibid.

17. The Body Mass Index (BMI) is defined as weight (in kilos) divided by height squared (in meters). For example, if a person's weight is 73 kilos and his height is 1.82 meter, his BMI is $73 /(1.82)^{2}=22.0$.

18. The calorie requirement for children below the age of 10 is derived in a different way. In terms of body weight, it is set at the median value of the weight for height range in found in a US reference population. The calorie requirement for physical activity it is set equal to "usual activity of children in affluent societies.... plus 5 per cent allowance for desired activity" (FAO 1996, ibid.: 131).

19. That the cut-off points are derived this way is not explicitly reported in the official FAO documents but acknowledged by the chief statistician at the FAO (L. Naiken 1998, ibid.). This kind of procedure for estimating the calorie requirements for individuals was originally proposed by P. V. Sukhatme (1961, ibid.) and is also suggested in a report from a nutritionist expert consultation group (FAO/WHO/UNU, Energy and Protein Requirements, Technical Report Series, 724 (WHO, Geneva, 1985: 14-19) set up as part of the preparations for The $5^{\text {th }}$ World Food Survey (FAO 1987). The same statistical procedure is commonly used in related areas. For instance, most of the anthropometric norms used to assess the nutritional or health status of young children are derived in this manner, i.e. the norms are set as two or three standard deviations from the median height or weight in a reference population.

20. Some of these details are found in the appendix on "methodology for assessing food inadequacy" in FAO 1996, ibid. The manual for planners and nutritionists, entitled Human Energy Requirements (Oxford: Oxford University Press, 1990), commissioned by the FAO and written by W. P. T. James and E. C. Schofield, contains most of the base data used by the FAO, but the details of how these data are used to set up the calorie cut-off points are not published.

21. FAO 1996, ibid.: 117.

22. See FAO/WHO/UNU 1985, ibid.: Annex 5; and James and Schofield 1990, ibid.

23. L. Naiken 1998, ibid.

24. "Economically necessary" work is, hence, equated with 8 hours per day of "moderately heavy" manual work. This definition of "economically necessary" has little to do with economics, since it does not allow for the fact that workers within and across countries have different productivity and, hence, income. The FAO definition is normative: people should be able to work in moderately heavy activities for normal hours.

25. FAO 1996, ibid.: 117-118.

26. $\mathrm{FAO} / \mathrm{WHO} / \mathrm{UNU} 1985$, ibid.: 16-19.

27. In the previous applications of joint-distribution approaches for estimating the prevalence of undernutrition and "calorie gaps", similar results are reported (S. Reutlinger and H. Alderman 1980, ibid.; N. C. Kakwani 1992, ibid.). It is hence puzzling that the FAO has chosen to use the biased cut-off-point model, citing lack of data as the justification, when it in fact has assigned a value to one of the two "missing" parameters $\left(\mathrm{CV}_{\mathrm{x}}=0.075\right)$, and that it has been known since long that the value of the other parameter $(\rho)$ matters only marginally for the size of the POU estimates. The latter result further implies that the data requirements are basically the same $\left(\mu_{\mathrm{y}}, \mu_{\mathrm{x}}, \mathrm{CV}_{\mathrm{y}}\right.$ and $\left.\mathrm{CV}_{\mathrm{x}}\right)$ with the two estimation methods.

28. L. Naiken (1998, ibid.: 114) notes, however, that "among other analysts...of particular concern was the fact that the [FAO] approach appeared to ignore the risk of inadequacy among individuals whose intakes are within the range of variation in requirement". This concern is thus supported by the above findings. 
29. Since the FAO does not publish the detailed data it has used for deriving the POU estimates for individual countries, there is no possibility to re-estimate these results with the "unbiased" method.

30. For a succinct attempt to bring some clarity into this sometime confusing controversy, see S. R. Osmani, "On Some Controversies in the Measurement of Undernutrition," in Nutrition and Poverty, ed. S. R. Osmani (Oxford: Clarendon, 1992); also see T. N. Srinivasan 1992, ibid. for a defence of the intra-individual-adaptation theory.

31. See, e.g., J. E. Hayter and C. J. K. Henry, "A Re-examination of Basal Metabolic Rate Predictive Equations: The Importance of Geographical Origin of Subjects in Sample Selection," European Journal of Clinical Nutrition, 48 (1994) and P. S. Shetty, C. J. K. Henry, A. E. Black, and A. M. Prentice, "Energy Requirements of Adults: An Update on Basal Metabolic Rates (BMR) and Physical Activity Levels (PALs)," European Journal of Clinical Nutrition (supplement), 23 (1996).

32. L. Naiken 1988, ibid.: iii.

33. The use of the household as the unit of observation means that the study of intra-household allocation of nutrients, and along gender lines, is beyond the reach of the FAO method. The significance of considering intra-household allocation has been highlighted in several studies (e.g. J. R. Behrman, ”Nutrition, Health, Birth Order and Seasonality: Intrahousehold Allocation in Rural India," Journal of Development Economics, 28 (1988); J. R. Behrman, "Intrahousehold Allocation of Nutrients in Rural India: Are Boys Favored? Do Parents Exhibit Inequality Aversion?," Oxford Economic Papers, 40 (1988); J. R. Behrman and A.B. Deolalikar, "The Intrahousehold Demand for Nutrients in Rural South India: Individual Estimates, Fixed Effects and Permanent Income," Journal of Human Resources, 25 (1990).; M. M. Pitt, M. R. Rosenzweigh, and M. N. Hassan, "Productivity, Health and Inequality in the Intrahousehold Distribution of Food in Low Income Countries," American Economic Review, 80 (1990); L. J. Haddad and R. S. M. Kanbur, "How Serious is the Neglect of Intrahousehold Inequality?,” Economic Journal, 100 (1990); L. J. Haddad and R. S. M. Kanbur, "Intrahousehold Inequalities and Different Welfare Levels: Energy Intake and Energy Expenditure Data from the Philippines," Oxford Bulletin of Economics and Statistics, 57 (1995); R. S. M. Kanbur, "Children and Intrahousehold Inequality: A Theoretical Analysis," Choice, Welfare and Development: A Festschrift in Honour of Amartya Sen, ed. K. Basu, et al. (Oxford: Clarendon, 1995); A. Farmer and J. Tiefenthaler, "Fairness Concepts and the Intrahousehold Allocation of Resources," Journal of Development Economics, 47 (1995). Gender issues are discussed in P. Svedberg, "Undernutrition in Sub-Saharan Africa: Is There a Gender Bias?," Journal of Development Studies, 26 (1990); P. Svedberg, "Gender Bias in Sub-Saharan Africa: Reply and Further Evidence," Journal of Development Studies, 32 (1996).

34. These data are from $\mathrm{FAO} / \mathrm{WHO} / \mathrm{UNU} 1985$, ibid.

35. UN, Demographic Yearbook 1997 (United Nations, New York, 1997).

36. See FAO 1996 ibid.: 133-142. In S. Reutlinger and H. Alderman (1980, ibid.) calorie distribution across broad income groups (not households as in FAO and in this study) was derived from estimates of the distribution of incomes. The authors themselves discussed the hazards involved in using this approach; further assessments are found in H. E. Bouis and L. J. Haddad, "Are Estimates of Calorie-Income Elasticities too High? A Recalibration of the Plausible Range," Journal of Development Economics, 39 (1992); H. E. Bouis, ”The Effects of Income on the Demand for Food in Poor Countries: Are our Food Data Bases Giving us Reliable Estimates?," Journal of Development Economics, 44 (1994); Kakwani 1992, ibid.; and P. Svedberg 2000, ibid.: ch. 4).

37 FAO 1992, ibid.

38. See W. P. T. James et al., "Definition of Chronic Energy Deficiency in Adults," European Journal of Clinical Nutrition, 42 (1988).

39. FAO/WHO/UNU 1985, ibid.: 73.

40. See D. L. Pelletier 1994, ibid.; and P. Svedberg 2000, ibid. 
41. In their joint assessment of the causes of mortality, the WHO and the IBRD find that 0.8 and 0.6 per cent of all deaths in Sub-Saharan Africa and India are directly attributable to "proteinenergy malnutrition" (WHO, World Health Report 1999 (World Health Organisation, Geneva, 1999: Appendix Table 2). In absolute numbers, these percentages translate into 77,000 and 56,000 deaths, respectively. Under- and malnutrition are, of course, contributing factors in many deaths caused by disease, but are not the direct cause.

42. P. Svedberg 2000, ibid.: chs. 6-7.

43. R. E. Evenson and C. E. Prey, "Measuring Food Production (with Reference to South Asia)," Journal of Development Economics, 44 (1994).

44. A. Heston, "A Brief Review of some Problems in Using National Account Data in Level of Output and Growth Studies," Journal of Development Economics, 44 (1994).

45. Estimates of calorie consumption from Food Consumption Surveys have been contrasted to the calorie supply data from the FAO. Estimates from a large number of countries often show marked differences between the two sets of estimates for given years (E. A. Dowler and Y. O. Seo, "Assessment of Energy Intake: Estimates of Food Supply vs Measurement of Consumption," Food Policy, 10 (1985); FAO, "A Comparative Study of Food Consumption Data from Food Balance Sheets and Household Surveys," Economic and Social Development Paper, 34 (Rome, 1983). However, there is no systematic sign pattern in the differences, and hence not possible to conclude from consumption surveys that the FAO has systematically over- or underestimated calorie availability. Moreover, consumption surveys are generally not more reliable than the FAO Food Balance Sheets.

46. FAO 1996, ibid.: 141-142.

47. The regression slope for intake as a function of minimum requirement can be expressed as (also see Figure 1): $\beta=\rho\left[\mathrm{CV}_{\mathrm{y}} / \mathrm{CV}_{\mathrm{x}}\right]\left[\mu_{\mathrm{y}} / \mu_{\mathrm{x}}\right]$. The high value of the ratio $\left[\mathrm{CV}_{\mathrm{y}} / \mathrm{CV}_{\mathrm{x}}\right]$, derived from the FAO base data (about 4.0), means that $\beta$ becomes very high (between 2.0 and 4.9). Such high $\beta$ 's imply that undernutrition is heavily concentrated to the households with the lowest MPCCR. Why this should be the case is not evident and remains for the FAO to explain.

48. See L. Naiken 1998, ibid.

49. All the estimates in Table 6.B have been derived on the assumption that the correlation coefficient $\rho$ is 0.70 , but estimates were also derived on the alternative assumptions that $\rho$ is 0.50 and 0.90 , respectively (Appendix Table 2). This robustness test shows that the POU estimates are not sensitive to the values of $\rho$ in this range, which confirms our earlier findings (Table 2).

50. That the estimate for Sub-Saharan Africa is not as sensitive to altered parameter values depends mainly on the fact that the estimated (by FAO) national per-capita availability of calories is close to average per-capita requirement in this region, while not in the others. N. C. Kakwani (1992, ibid.) estimated POU in India on the basis of household survey data from 1970-71 with both an average-requirement-norm method and the joint-distribution method, assuming different distribution functions and alternative values of the parameters $\mathrm{CV}_{\mathrm{x}}$ and $\rho$ (but not $\mathrm{CV}_{\mathrm{y}}$ ). He found practically no difference in the ensuing POU estimates for the rural population; presumably also because his average-calorie-requirement norm was very close to the average rural intake in his data set. His estimates for the urban population, for which there was a significant difference between average intake and requirement, were much more sensitive to the value attached to the $\rho$ parameter.

51. The intricate reinforcing interactions between illness and poor nutrition have been known since long; see, e.g., N. S. Scrimshaw et al., Interaction of Nutrition and Infection (WHO, Geneva, 1959); J. R. Behrman, "The Action of Human Resources and Poverty on One Other," LSMS Working Paper, 74 (World Bank, 1990); P. Payne, "Assessing Undernutrition: The Need for a Reconceptualisation," in S. R. Osmani 1992, ibid.; and ACC/SCN, Fourth Report on the World Nutrition Situation (Geneva, 2000). For further analyses of the multifaceted web of reasons behind child growth failure, see various contributions to J. C. 
Waterlow (ed.), Linear Growth Retardation in Less Developed Countries, Nestlé Nutrition Workshop Series, 14 (New York: Raven Press, 1988); P. B. Eveleth and J. M. Tanner, Worldwide Variations in Human Growth (Cambridge: Cambridge University Press, 1990); and D. Maxwell et al., "Urban Livelihoods and Food and Nutrition Security in Great Accra, Ghana," IFPRI Research Report, 112 (Washington D.C., 2000).

52. The main reason that has been offered in the literature for the exceptionally poor anthropometric status of women in South Asia, especially in the form of stunting but also wasting, is their discriminated position, passed on from generation to generation (see V. Ramalingaswami, U. Jonsson, and J. Rohde, "The Asian Enigma," The Progress of Nations (UNICEF, New York, 1996); S. R. Osmani 1997, ibid; U. Ramakrishnan, R. Martorell, D. G. Schroeder, and R. Flores, "Role of Inter-generational Effects on Linear Growth," Journal of Nutrition, 129 (1999). There is also the possibility that the genetic potential for final growth in stature is lower in Asian populations than in other populations, but so far this is only a hypothesis.

53. For a detailed assessment of measurement errors and biases in athropometric indicators, see R. Bairagi, "Effects of Bias and Random Error in Anthropometry and in Age on Estimation of Malnutrition," American Journal of Epidemiology, 123 (1986); and G. C. Marks, J. P. Habicht, and W. H. Mueller, "Reliability, Dependability, and Precision of Anthropometric Measurements," American Journal of Epidemiology, 130 (1989) and on the representativity of anthropometric measures and their comparability with POU estimates, see P. Svedberg 2000, ibid.: ch. 11-13; and M. Nube, "Confronting Dietary Energy Supply with Anthropometry in the Assessment of Undernutrition Prevalence at the Level of Countries," World Development, 29 (2001).

54. More exact re-calculations have not been possible to undertake for the simple reason that the FAO has not published its data on the age composition of the population and the share of the per-capita calorie requirements in the cut-off-points that children account for.

55. Severe to moderate underweight among adult women (aged 20-49) is practically non-existent in Latin America. Observations from 11 countries, with about two-thirds of the population in the region, show on average 2 per cent to have a BMI below 17.0. In Latin America, the by far most serious nutrition problems are overweight and obesity. In 10 of the 11 countries (Haiti being the exception), the share of overweight women (BMI>25.0) is in the range 32 to 48 per cent and the share of obese women (BMI $>30.0$ ) is in the 8 to 13 per-cent range (ACC/SCN 2000, ibid.: Table 1.8).

56. While there are hardly any observations of the anthropometric status of male adults and old people of either sex, adolescents have been assessed in more than a dozen countries, mainly in Latin America (see FAO 1996, ibid.: Table 24; and ACC/SCN 2000, ibid.: Fig. 1.5). With one exception (stunting in India), these studies show adolescent males more frequently to be below the anthropometric norms in all the countries. This finding tentatively indicates that the conventional belief that women are the main victims of undernutrition (and poor health) may not stand up to closer scrutiny.

57. According to ILO estimates, the labour-market participation rates for women in Sub-Saharan African and Latin American countries are in the 50-70 per-cent range, while typically less than 20 per cent in most of South Asia and in the Middle East and North Africa.

58. For references, see n. 10 above.

59. The most striking discrepancy (in the unexpected direction) between the revised POU estimates and the anthropometric indicators is found for Sub-Saharan Africa (Table 7). This is a further indication that the national per-capita calorie availability estimates - the parameter that was unaltered - for this particular region has been underestimated by the FAO, as discussed in section V.D above.

60. It should be recalled that even if the aggregate food-supply-based approach for the estimation of undernutrition will be improved, it can not be of help for all the policy purposes for which nutritional indicators are needed. As underscored by the FAO (1996, ibid.: 120-127) itself, the method can only be used to estimate the proportion of calorie-deficient households (also 
see Figure 1), not for identifying specific undernourished households, signifying that the FAO approach is of no use for targeting interventions at the micro level. Moreover, since the household is the unit of assessment, the study of intra-household allocation of nutrients must rely on other methods (e.g. anthropometrics and/or household surveys). 


\section{SEMINAR PAPER SERIES}

The Series was initiated in 1971. For a complete list of Seminar Papers, please contact the Institute.

$\underline{1996}$

616. Assar Lindbeck:

617. Assar Lindbeck:

618. Javier Ortega:

619. Joakim Persson and Bo Malmberg:

620. Assar Lindbeck and Dennis J. Snower:

621. Paul Söderlind and Lars E.O. Svensson:

$\underline{1997}$

622. Assar Lindbeck:

623. John Hassler and José Vicente Rodriguez Mora:

624. Nils-Petter Lagerlöf:

625. Lars E.O. Svensson:

626. James E. Anderson:

627. Mårten Blix:

628. Assar Lindbeck and Dennis J. Snower:

629. Etienne Wasmer:
The West European Employment Problem. 31 pp.

Full Employment and the Welfare State. 22 pp.

How (Good) Immigration Is: A Matching Analysis. $30 \mathrm{pp}$.

Human Capital, Demographics and Growth Across the US States 1920-1990. 21 pp.

Centralized Bargaining, Multi-Tasking, and Work Incentives. 43 pp.

New Techniques to Extract Market Expectations from Financial Instruments. $47 \mathrm{pp}$

Incentives and Social Norms in Household Behavior. $12 \mathrm{pp}$.

Employment Turnover and Unemployment Insurance. $36 \mathrm{pp}$.

Strategic Saving and Non-Negative Gifts. 20 pp.

Inflation Targeting: Some Extensions. 43 pp.

Revenue Neutral Trade Reform with Many Households, Quotas and Tariffs. 36 pp.

Rational Expectations in a VAR with Markov Switching. $37 \mathrm{pp}$.

The Division of Labor Within Firms. 12 pp.

Can Labour Supply Explain the Rise in Unemployment and Inter-Group Wage Inequality in the OECD? 64 pp. 
630. Torsten Persson and Guido Tabellini:

631. John Hassler and Assar Lindbeck:

632. Michael Woodford:

633. Torsten Persson, Gérard Roland and Guido Tabellini:

634. Johan Stennek:

$\underline{1998}$

635. John Hassler and José V. Rodríguez Mora:

636. Jon Faust and

Lars E. O. Svensson:

637. Glenn D. Rudebusch and Lars E. O. Svensson:

638. Lars E. O. Svensson:

639. Lars Calmfors:

640. Assar Lindbeck:

641. Donald Brash:

642. Claes Berg and Lars Jonung:

643. Jürgen von Hagen:

644. Bennett T. McCallum and Edward Nelson:

645. Assar Lindbeck:

646. Lars E.O. Svensson:
Political Economics and Macroeconomic Policy.100 pp.

Intergenerational Risk Sharing, Stability and Optimality of Alternative Pension Systems. 38 pp.

Doing Without Money: Controlling Inflation in a Post-Monetary World. $62 \mathrm{pp}$.

Comparative Politics and Public Finance. 55 pp.

Coordination in Oligopoly. $14 \mathrm{pp}$.

IQ, Social Mobility and Growth. 34 pp.

Transparency and Credibility: Monetary Policy with Unobservable Goals. 40 pp.

Policy Rules for Inflation Targeting. 51 pp.

Open-Economy Inflation Targeting. 51 pp.

Unemployment, Labour-Market Reform and Monetary Union. $35 \mathrm{pp}$

Swedish Lessons for Post-Socialist Countries. 37 pp.

Inflation Targeting in New Zealand: Experience and Practice. $11 \mathrm{pp}$.

Pioneering Price Level Targeting: The Swedish

Experience 1931-1937. 50 pp.

Money Growth Targeting. 34 pp.

Nominal Income Targeting in an Open-Economy Optimizing Model. 48 pp.

Swedish Lessons for Post-Socialist Countries. $42 \mathrm{pp}$.

Inflation Targeting as a Monetary Policy Rule. $51 \mathrm{pp}$. 
647. Jonas Agell and Mats Persson:

648. Frederic S. Mishkin:

649. John B. Taylor:

650. Christopher J. Erceg, Dale W. Henderson and Andrew T. Levin:

651. Etienne Wasmer:

652. Daron Acemoglu and Fabrizio Zilibotti:

653. Argia Sbordone:

654. Martin Flodén and Jesper Lindé:

655. Thomas $P$. Tangerås:

656. Peter Svedberg:

657. Lars Calmfors:

658. Torsten Persson and Guido Tabellini:

659. Lars Calmfors:

660. Daron Acemoglu and Fabrizio Zilibotti:

661. Ramon Marimon and Fabrizio Zilibotti:

662. Yves Zenou:
Tax Arbitrage and Labor Supply. 35 pp.

International Experiences With Different Monetary Policy Regimes. 47 pp.

The Robustness and Efficiency of Monetary Policy Rules as Guidelines for Interest Rate Setting by The European Central Bank. 39 pp.

Tradeoffs Between Inflation and Output-Gap Variances in an Optimizing-Agent Model. 43 pp.

Labor Supply Dynamics, Unemployment and Human Capital Investments. 36 pp.

Information Accumulation in Development. 43 pp.

Prices and Unit Labor Costs: A New Test of Price Stickiness. 33 pp.

Idiosyncratic Risk in the U.S. and Sweden: Is there a Role for Government Insurance? 30 pp.

On the Role of Public Opinion Polls in Political Competition. 36 pp.

841 Million Undernourished? On the Tyranny of Deriving a Number. 39 pp.

Macroeconomic Policy, Wage Setting and Employment What Difference Does the EMU Make? 52 pp.

The Size and Scope of Government: Comparative Politics with Rational Politicians. 47 pp.

Monetary Union and Precautionary Labour-Market Reform. $10 \mathrm{pp}$.

Productivity Differences. 48 pp.

Unemployment vs. Mismatch of Talents: Reconsidering Unemployment Benefits. 35 pp.

Urban Unemployment and City Formation. Theory and Policy Implications. 35 pp. 
663. Stefan Palmqvist:

664. Kjetil Storesletten:

665: John Hassler, José V. Rodríguez Mora, Kjetil Storesletten and Fabrizio Zilibotti:

1999

666. Michael Woodford:

667. Lars E.O. Svensson:

668. Assar Lindbeck:

669. Lars E.O. Svensson:

670. Assar Lindbeck and Solveig Wikström:

671. Lars E.O. Svensson:

672. Glenn Rudebusch and Lars E.O. Svensson:

673. Lars Svensson:

674. Thomas P. Tangerås:

675. Bertil Ohlin:

676. Assar Lindbeck:

677. Assar Lindbeck and Solveig Wikström:

678. Andrew K. Rose:

679. Jonas Agell, Mats Persson and Hans Sacklén:
Why Central Banks Announce Their Objectives: Monetary Policy with Discretionary Signalling. 22 pp.

Sustaining Fiscal Policy Through Immigration. 41 pp.

Equilibrium Unemployment Insurance. 56 pp.

Optimal Monetary Policy Inertia. 112 pp.

Monetary Policy Issues for the Eurosystem. 54 pp.

The Price in Economic Sciences In Memory of Alfred Nobel 1969-1998. 28 pp.

The Equilibrium Degree of Transparency and Control in Monetary Policy. 25 pp.

The ICT Revolution in Consumer Product Markets. 23 pp.

Does the $P^{*}$ Model Provide Any Rationale for Monetary Targeting? $14 \mathrm{pp}$.

Eurosystem Monetary Targeting: Lessons from U.S. Data. 29 pp.

Price Stability as a Target for Monetary Policy Defining and Maintaining Price Stability. 50 pp.

Collusion-Proof Yardstick Competition. 33 pp.

The Theory of Interregional Exchange. 42 pp.

Unemployment - Structural. 16 pp.

ICT and Household-Firm Relations. 23 pp.

One Money, One Market: Estimating the Effect of Common Currencies on Trade. 40 pp.

Labor Supply Prediction When Tax Avoidance Matters. $36 \mathrm{pp}$. 
680. Lars E.O. Svensson:

$\underline{2000}$

681. Lars E.O. Svensson:

682. Jonas Agell and Mats Persson:

683. Harry Flam and Per Jansson:

684. Harry Flam and M. June Flanders:

685. Assar Lindbeck:

686. Mats Persson:

687. Lars E.O. Svensson:

688. Lars E.O. Svensson and Michael Woodford:

$\underline{2001}$

689. Lars E.O. Svensson and Michael Woodford:

690. Lars Calmfors

691. Assar Lindbeck and Sten Nyberg

692. Lars Calmfors and Åsa Johansson

693. Peter Svedberg
How Should Monetary Policy Be Conducted in an Era of Price Stability? $50 \mathrm{pp}$.

The First Year of the Eurosystem: Inflation Targeting or Not? $11 \mathrm{pp}$.

On the Analytics of the Dynamic Laffer Curve. 25pp.

EMU Effects on International Trade and Investment. 42 pp.

The Young Ohlin on the Theory of "Interregional and International Trade". $18 \mathrm{pp}$.

Pensions and Contemporary Socioeconomic Change. 27 pp.

Five Fallacies in the Social Security Debate. 16 pp.

The Zero Bound in an Open Economy: A Foolproof Way of Escaping from a Liquidity Trap. 44 pp.

Indicator Variables for Optimal Policy. 43 pp.

Indicator Variables for Optimal Policy under Assymetric Information. $28 \mathrm{pp}$.

Wages and Wage-Bargaining Institutions in the EMU-A Survey of the Issues. $36 \mathrm{pp}$.

Raising Children to Work Hard: Altruism, Work Norms and Social Insurance. 37 pp.

Unemployment Benefits, Contract Length and Nominal Wage Flexibility. 36 pp.

Undernutrition Overestimated. 38 pp.

ISSN 0347-8769

Stockholm, 2001

Institute for International Economic Studies 